\title{
الاتجاهات الحديثة في تسويق خدمات مؤسسات ومراكز المعلومات
}

\section{Recent Trends in Marketing the Services of Institutions and Information Centers}

\author{
إعداد: \\ الباحثة/ نجاة عايض الحربي \\ بكالوريوس في علم المعلومات، دبلوم عالي في التربية، المملكة العربية السعودية \\ الباحثة/ رنا عمر باهبري \\ ماجستير في إدارة المعلومات، المملكة العربية السعودية \\ الباحثة/ مرام محمد القثامي \\ ماجستير في إدارة المعلومات، المملكة العربية السعودية

$$
\text { الباحثة/ هالة عبد الرشيد تركستاني }
$$ \\ ماجستير في إدارة المعلومات، المملكة العربية السعودية
}

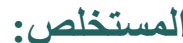

تهدف الدر اسة إلى معرفة الاتجاهات الحديثة المستخدمة للتسويق لخدمات مؤسسات المعلومات، ومعرفة التجارب الحالية للمؤسسات المعلو مات في استخدام التقنيات الحديثة، ومدى تأثير التقنية والثبكات الاجتماعية على مفهوم التسويث لخدمات المعلومات. حيث تم استخدام منهج تحليل المحتوى و الاطلاع على التجارب الحالية في استخدام التقنيات الحديثة في التسويق لخدمات مؤسسات المعلومات ووجد أن التقتيات عديدة وتم استعر اضها واستعر اض النماذج المطبقة ومن ضمن التقنيات الحديثة الهولوجر ام و الو اقع المعزز و العرض البانور امي وغيره. حيث توصلت الباحثات أن التقنيات الحديثة طريقة سريعة لنشر و الترويج لخدمات ومؤسسات المعلومات بطريقة مبتكرة وملفته وتعتبر عامل جذب للمستفيدين وطريقة حديثة لكسب العملاء و المستفيدين، حيث أن قلة من مؤسسات المعلومات أدخلت التقنيات الحديثة للترويج لخدماتها، وتعتبر ثقافة التسويق لخدمات مؤسسات المعلومات تم اقتصار ها على نشر الخدمات على حسابات مو اقع التو اصل الاجتماعي التابعة لمؤسسات المعلومات. وتوصي الباحثة: بتكثيف الجهود لاستخدام التقنيات الحديثة في التسويق و الترويج للخدمات بإقامة الحملات و عرض الخدمات عن طريق هذه التقنيات لاستقطاب المستفيدين، والاطلاع المسنمر على التقنيات الحديثة و عمل در اسة لمدى فعاليتها، والعمل

على تدريب العاملين و إخصائي المعلومات على التعامل مع التقنية وتبني طرق التسويق الحديثة ومعرفة أساليب التسويق وتسخير ها لترويج لخدمات مؤسسات المعلومات.

الكلمات المفتاحية: مؤسسات المعلومات، خدمات المعلومات، التسويق، تسويق خدمات المعلومات، الو اقع الافتر اضي، الواقع المعزز، العرض البانوارمي، الهولوجر ام. 


\section{Recent Trends in Marketing the Services of Institutions and Information Centers}

\section{Abstract:}

The study aims to know the modern trends used in marketing for information institutions services, Knowing the current experiences of information institutions in the use of modern technologies and the impact of technology and social networks on the concept of marketing for information services. The content analysis approach was used and the current experiences in the use of modern technologies in marketing the services of information institutions were used It was found that the techniques are many, and they were reviewed and the models applied, and among the modern technologies are the hologram, augmented reality, panoramic View, and others. The researchers found that modern technologies are a quick way to disseminate and promote information services and institutions in an innovative and attractive way, It is an attractive factor for beneficiaries and a modern way to gain customers and beneficiaries. It is considered an attractive factor for beneficiaries and a modern way to gain customers and beneficiaries, as few information institutions have introduced modern technologies to promote their services. The culture of marketing for information services has been limited to publishing services on social media accounts of information institutions. The researchers recommend: to intensify efforts to use modern technologies in marketing and promoting services by conducting campaigns and offering services through these techniques to attract beneficiaries. Continuous access to modern technologies and a study of their effectiveness. Work on training employees and information specialists to deal with technology, adopting modern marketing methods, knowing marketing methods, and harnessing them to promote the services of information institutions.

Key word: Information Institutions, Information Services, Marketing, Information Services Marketing, Virtual Reality, Augmented Reality, Panoramic View, Hologram.

تو اجه مؤسسات المعلومات تحديات كبيرة فرضتها البيئة الإلكترونية ومنها: إرضاء المستفيدين الذين يميلون لاستخدام منصات الإنترنت لتلبية حاجتهم المعلوماتية فلجأت العديد من مؤسسات ومر اكز المعلومات لتطوير أساليبها التسويقية وإدخال التقنيات

$$
\text { الحديثة في الترويج للخدمات التي تقدمها حتى تبقي على المنافسة وتستقطب العملاء و المستفيدين. }
$$


ونلاحظ أن مؤسسات المعلومات شهدت تطور ملحوظ فتقديمها لخدماتها لكن ماز الت القصور واضحة في تفعيل واستخدام التقنيات الحديثة في تقديم خذمات المعلومات في بعض مؤسسات المعلومات في وقتنا الحالي.

حيث تستعرض الدر اسة عن نبذة عن مؤسسات المعلومات وخدمات المعلومات، من ثم التطرق إلى مفهوم التسويق وتوظيف الثبكات الاجتماعية واستخدامها في التسويق، يلي ذلك استعر اض لأهم و أثنهر وسائل التو اصل الاجتماعي، ثم ننتقل إلى توضيح بعض التقنيات الحديثة التي تستخدم في تسويق خدمات المعلومات مع النماذج التطبيقية على كل اتجاه منها. أهمية أبحث: تكمن أهمية البحث في معرفة التقنيات الحديثة المستخدمة في مؤسسات المعلومات ومدى تطبيقها على أرض الو اقع في تقديم خدمات مؤسسات المعلومات. حيث تعتقد الباحثات أن النتائج التي سوف تسفر عنها الدر اسة ستقدم قيمة مضافة تثري مجال البحث العلمي.

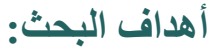

- معرفة التقنيات المستخدمة للتسويق لخدمات المعلومات. - معرفة التجارب الحالية للمؤسسات المعلومات في استخدام التقنيات الحديثة معرفة مدى نأثير التقنية والثبكات الاجتماعية على تسويق خدمات المعلومات

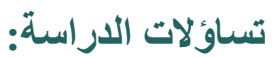
- ما التقنيات المستخدمة للتسويق لخدمات المعلومات؟ - ما تأثنير التقنية والثبكات الاجتماعية على التسويق لخدمات المعلومات؟ منهج وأدوات البحث: المنهج: نم استخدام منهج تحليل المحتوى ومر اجعة الأدبيات السابقة.

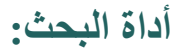
1. الملاحظة كأداة هامة لتحليل المحتوى.

$$
\text { 2. ت تقييم الحسابات والمواقع. }
$$

حدود الدراسة: الحدود الموضوعية: يغطي هذا البحث عدة مو اضيع في مفاهيم مؤسسات المعلومات، خدمات المعلومات، تسويق المعلومات، التقنيات الحديثة، الثبكات الاجتماعية. الحدود الزمانية: تم إجر اء هذا البحث في عام 1443 هـ. 
ـمؤسسات المعلومات: المؤسسات أو الهيئات أو المكتبات (الوطنية، المتخصصة، العامة، المدرسية، الجامعية)، التي تقوم بحصر مصادر المعلومات المختلفة بهدف تنظيمها و إتاحتها لخدمة المستفيدين. (العريشي؛ الغامدي، 2015) -خدمات المعلومات: هي خدمات معلوماتية تقدم عبر قسم أو مركز أو إدارة في المؤسسة أو يمكن عبر وكالة مستقلة تقدم خدماتها المعلوماتية بمقابل. (السريحي،2018)

-تسويق المعلومات: يرتبط مفهوم تسويق المعلومات ارتباطاً وثيقاً بخدمات المكتبات، إذ بعتبر بمثابة وظيفة خاصّة بالمكتبة تسعى من خلالها إلى رفع أعداد المستقيدين من خدماتها عبر انتهاجها مجمو عة من البر امج والأنشطة و العمليّات وتسخير ها بما بتماثـى مع مصلحة المكتبة في إنهار خدماتها و إيصالها إلى مستخدميها كالمكتبات البريديّة، و النشر ات، و المطويات، و المقالات، و التقارير السنويّة، و عقد الندوات و المؤتمر ات، وغير ها الكثير من الأساليب. (الحياري، 2018)

ـالثبكات الاجتماعية: ذكر كل من (عبد الهادي، 2017) و (خبر اني و القرني، 2017) أن الثبكات الاجتماعية هي أحد تطبيقات الويب (2.0)، و هي من أكثر المواقع (Websites) تفاعلية وأكثر قربًا من المستخدم، فبإمكانه الإضافة إلى محتوى الصفحة و أيضا التغيير في محتوى الموقع، كما تتيح للأشخاص التعريف عن أنفسهم ومشاركة اهتماماتهم و الصور و الفيديو و الملفات و

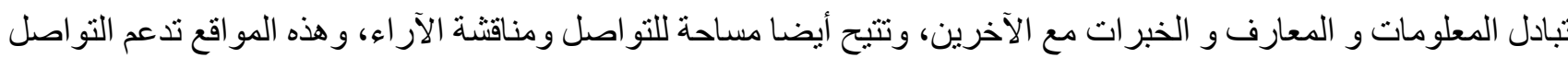
Communication و محادثات فورية (Chats) و إنشاء مجمو عات (Groups) و البريد الإلكتروني (Email) و وصفحات للأفر اد

\section{أو المؤسسات. الاراسات السابقة:}

در اسة (الخالدي،2018) بعنوان تسويق خدمات المعلومات في المكتبات ومر اكز المعلومات: المكتبة المركزية أنموذجاوتهدف الدر اسة على التسويق لخدمات المعلومات و أهميتها في المكتبات الجامعية من حيث السياسات و الخطط التي تضعها المكتبة لتحقيق أفضل أهدافها. وخرجت الدراسة بجملة من النتائج والتوصيات ومنها: نتيجة لتز ايد الاهتمام بعنصر التسويق على المستوى العالمي فقد أصبح حقلاً من حقول المعرفة و الدر اسة في معظم المكتبات الجامعية، عدم معرفة أكثر من بحثين عن مفهوم التسويق في مجال خدمات المعلومات. ويوصى الباحث: اطلاع ومعرفة المتخصص في مجال المكتبات على عنصر التسويق. توسيع الخدمات التسويقية مثل الإحاطة الخارجية و البث الانتقائي للمعلومات على مستوى الكليات و المكتبات. در اسة (احديد،2013) بعنوان تسويق خدمات المكتبات والمعلومات: حيث تناولت هذه الدراسة موضوع التسويق بشكل عام ومفهوم تسويق خدمات المكتبات و المعلومات بشكل خاص وما يجب أن تقوم به المكتبة في هذه الحالة. وتوصلت الدر اسة أن استخدام التسويق في المكتبات لا يؤدي فقط إلى حل المشكلات المادية ولكنه يزيد من عدد مستخدمي المكتبة وهو الهدف الأساس من وجود المكتبة. وأن مستقبل المكتبات لن يككن باهراً وملبياً لطموحات الأجيال القادمة إذا بقيت تعمل في نطاق الأساليب 
الهجلة الدولية لنشر البحوث والدراسات

International Journal of Research and Studies Publishing
المجلد الثالث - الإصدار الثامن والعشرون

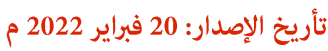

أولَا: مؤسسات المعلومات وخدمات المعلومات

$$
\text { خ مؤسسات المعلومات }
$$

وضح (السريحي، 2018) أن مؤسسات المعلومات هي " تللك المؤسسات التي تتعامل مع المعلومات كمحور عمل انتاجًا وتحليًا وتنظيمًا وخدمة ونشر ا وبثًا وتسويقًا " وصنّفها لعدة فئات كما هو موضح بالثكل التالي:

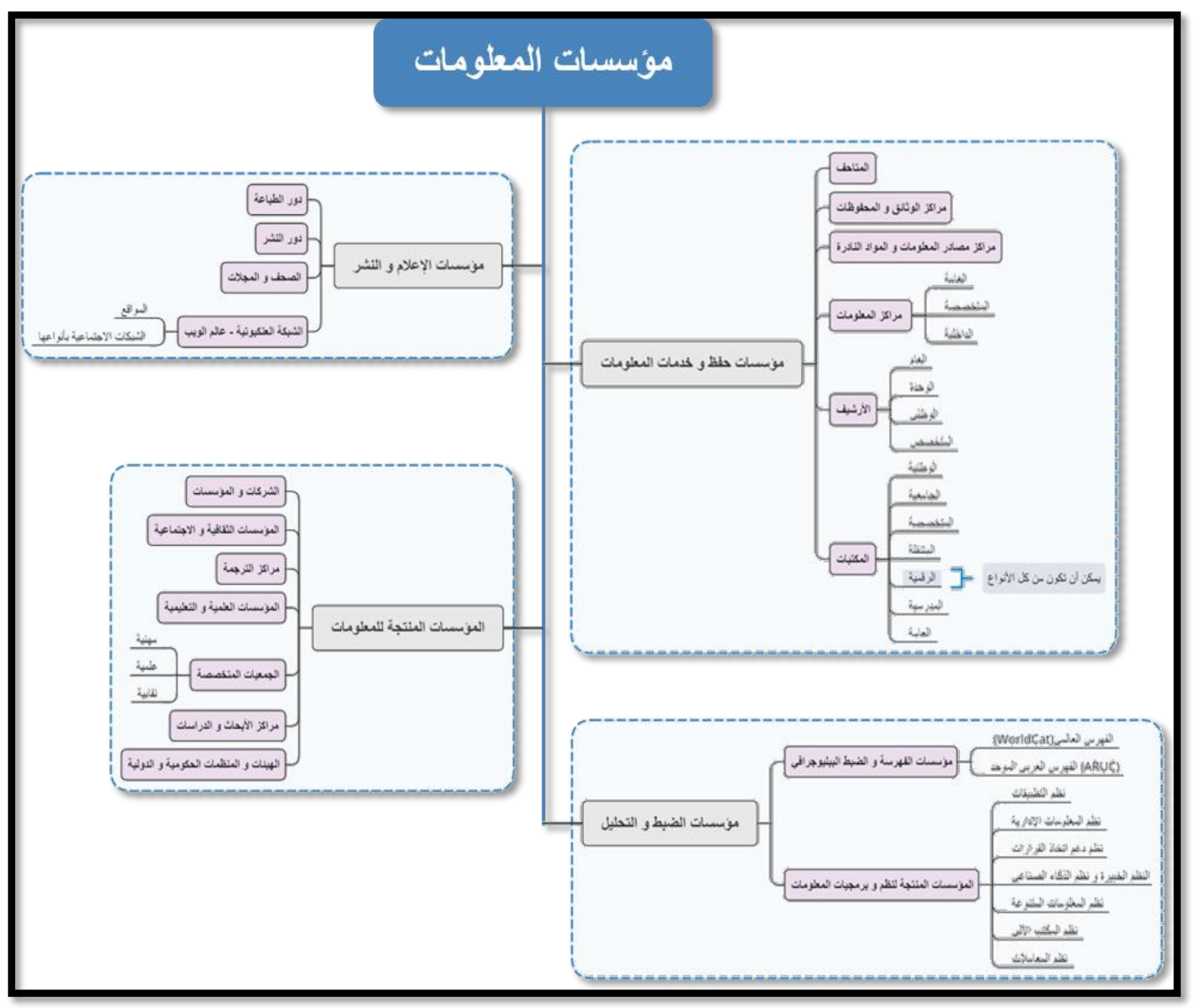

$$
\text { صورة (1): تصنيف مؤسسات المعلومات }
$$




\section{Information Services خدمات المطومات}

ويرى (خبر اني و القرني، 2017) أنها " الأنشطة والعمليات والوظائف و الإجر اءات والتسهيلات التي تقوم بها المكتبات ومر اكز المعلومات، ممثلة في العاملين لديها من أجل خلق الظروف المناسبة لوصول الباحث أو إثباع ما لديه من حاجات

\section{ثانيًا: تسويق خدمات المعلومات وتأثير التقنية والشبكات الاجتماعية}

\section{Marketing التسويق}

تعرفها الجمعية الأمريكية للتسويق هو عبارة عن: نشاط، مجموعة من المؤسسات، و عمليات الإنثاء، تواصل، توصيل، وذللك لتبادل العروض التي لها قيمة للزبائن، العملاء، الثركاءو المجتمع ككل. (AMA,2013)

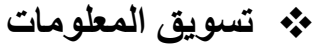

نظر اً لأهيّة تسويق المعلومات فقد ظهر ما يسمّى بنظام المعلومات التسويقيّة، حيث يعتبر وسيلة هامّة لتسيير عمليّة اتخاذ القرارات ذات العلاقة بالتسويق، ومن أبرز القرارات المتعلّقة بالتسويق: الإعلان، والسعر، والترويج، والتوزيع، والبيع. (الحياري، 2018)

إستراتيجية تسويق خدمات المعلومات Marketing Strategy for Information Services: " الخطة الطويلة الأجل التي ترشد وتوجه مجهودات تسويق خدمات المعلومات عن طريق تحقيق التوازن بين المزيج التسويقي والمتغيرات البيئية المختلفة المؤثرة في القرار التسويقي". (الهلال، 2017)

و حريّ بنا توضيح نبذة عن ماهية المزيج التسويقي Marketing Mix و مكوناته: حيث وضح (المزيج التسويقي Marketing Mix و المتر ابطة والتي تعتمد على بعضها البعض بغرض أداء الوظيفة التسويقية على النحو المخطط حيث يجد المنسق نفسه في مو اجهة العديد من الخيار ات في المنتجات وطرق التوزيع و أساليب التسعير و الوسائل الترويجية وبما يتناسب مع ظروف المنشأة الخاصة وما يحيط بها من تغير ات بيئية و على المسوق أن يمزج هذه العناصر بالطريقة التي تتناسب مع المنشأة و الموقف التسويقي و المعطيات البيئية المتغيرة ". ويتكون من أربعة عناصر كما يلي:

1- المنتج Product: وهو ما يتم تقديمه من سلع Goods أو خدمات Services أو أفكار Ideas أو أي تركيبة Combination 2- التوزيع Distribution: ويعني " هو الكيفية التي تصل بها السلع أو الخدمات إلى العميل المرتقب في المكان و الوقت المناسبين و الكيفية التي تضمن إدر اكها ". 
3- التسعير Pricing: " هو عملية موائمة المنافع التي يحصل عليها المشتري أو المستهلك بالقيم النقدية التي يمكن أن

$$
\text { بدفعهاو هي عملية معقدة ترنبط باعتبار ات اقتصادية وسلوكية متعددة ". }
$$

4- الترويج Promotion: ويشمل " عمليات اتصال تستهدف التأثير على المستهلك المستهدف لاستمالة سلوكه الثرائي

$$
\text { ويتم الترويج بأساليب كثيرة ومتعددة ومن أبرز ها الإعلان و الدعاية التجارية ". }
$$

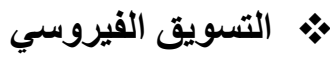

- هو أحد المصطلحات المستخدمة في عالم التسويق الإلكتروني، وهي إستر اتيجية تسويقية تهدف للوصول إلى جمهور

الأفر اد المستهدفين الكترونياً عن طريق رسالة إلى شخص ما في الثبكة الاجتماعية. - هو حملة مخططة ومنتظمة تهدف إلى نشر المعلومات من شخص إلى شخص آخر، عن طريق العدوى التي ينتج عنها فو ائد عظيمة ذات أثر مضاعف. - طريقة جديدة لزيادة اختر اق السوق وبناء وعي للصنف من خلال استخدام الإنترنت. (أحمد، 2017)

$$
\begin{aligned}
& \text { أهمية التسويق الفيروسي } \\
& \text { 1. سهولة وصوله إلى الفئات المستهدفة. }
\end{aligned}
$$

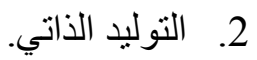

$$
\begin{aligned}
& \text { 3. يتناسب مع عصر الإنترنت. } \\
& \text { 4. كثرة الإعلانات الدعائية. } \\
& \text { 5. انخفاض التكاليف. } \\
& \text { أهداف التسويق الفيروسي }
\end{aligned}
$$

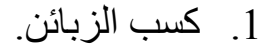

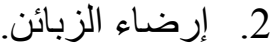

$$
\begin{aligned}
& \text { 3. و لاء الزبائن. } \\
& \text { 4. درجة الشعبية بين الزبائن. } \\
& \text { أدوات التسويق الفيروسي } \\
& \text { 1. محركات البحث و البريد الإلكتروني. }
\end{aligned}
$$

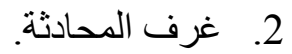

$$
\begin{aligned}
& \text { 3. العروض المجانية. } \\
& \text { 4. البر امج المعدة لهذا الغرض. }
\end{aligned}
$$

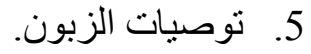

$$
\begin{aligned}
& \text { 6. رسائل أخباريه. (الطائي؛ آخرون، 2016) }
\end{aligned}
$$




\section{ب استخدام الشبكات الاجتماعية في تسويق خدمات المعلومات}

يصف (خبر اني و القرني، 2017) أن عملية تسويق خدمات المعلومات في المكتبات عبر وسائل التواصل الاجتماعي بأنها: " عملية التركيز على التواصل و التعاون وتوليد المحتوى المناسب للمستخدمين وذلك من خلال استخدام مجموعة من البرامج و التطبيقات ووسائل الأعلام الاجتماعية وذلك بهدف رفع مستوى الوعي لاى المستفيدين بخدمات المكتبة ومواردها المتوفرة مع ون القدرة على تعزيز الاستخدام الفعال لهذه الخدمات و الموارد من أجل تحسين الوعي و التعلم لديهم".

$$
\text { • استخدام التقتية الحديثة في التسويق }
$$

مما لا شك فيه أن التقنية ما باتت تفاجئنا يومًا بعد يوم بالعديد والعديد من التطور ات التي لن تتوقف ومن هذه التقنيات

$$
\begin{aligned}
& \text { الحديثة: } \\
& \text { 1- الو اقع الافتر اضي. } \\
& \text { 2- الو المع المعزز. } \\
& \text { 3- العرض البانور امي. } \\
& \text { 4- العرض البانور امي التفاعلي. }
\end{aligned}
$$

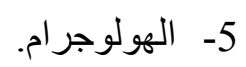

وسيتم توضيحها لاحقًا في الجزء الرابع الذي يتناول الاتجاهات الحديثة في تسويق خدمات المعلومات.

ثالثًا: الثبكات الاجتماعية

\section{* * مأنواع الشبكات الاجتماعية}

1. شبكات شخصية: خاصة بأثخاص معينين وهي تقتصر على مجمو عة من الأصدقاء و المعارف وتعمل على التو اصل

الاجتماعي فيما بينهم بجميع الأشكال حيث يتم إتاحة ملفات للصور الثخصية و المناسبات الاجتماعية فيما بينهم.

2. شبكات خاصة: بفئات موضو عية معينة و هذه الثبكات نثأت لتجميع بعض المهنمين بموضو عات معينة مثل المهتمين

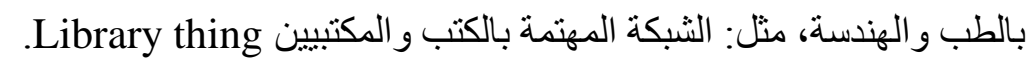

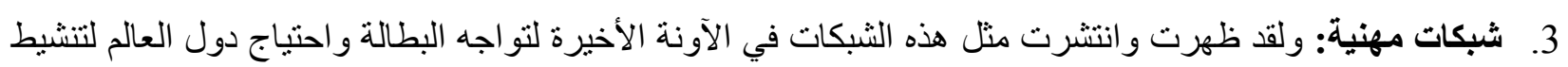

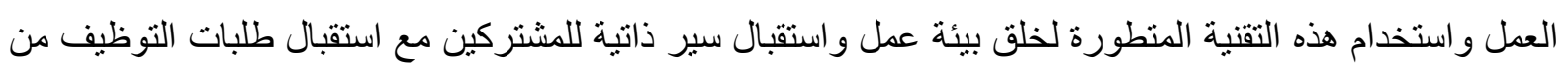

جانب الثركات، مثل: شبكة Linked in. (الرندي،2017)

\section{ثز مزايا وفوائد الشبكات الاجتماعية}

وضح (Jackson, 2017) و (Weller, 2018) أن للثبكات الاجتماعية مز ايا وفو ائد في عدة نواجٍ نذكر منها المز ايا المتعلقة: 
خدمة العملاء (Customer Service)

1. إدارة السمعة: حيث يمكن من خلالها مر اقبة الـ Mentions بحيث يمكن التجاوب بسر عة مع شكاوى العملاء أو

$$
\text { مشكلاتهم. }
$$

2. تعزيز مشاركة العملاء: حيث يمكن من خلالها التفاعل مع العملاء و الحصول على ردود منهم Feedback مما له الأثر البالغ في زيادة معدل النجاح وتطور العلاقة مع العملاء وبناء الولاء و الوفاء لثعور هم باهتمام المؤسسة

بهم (Dukart, 2018).

3. سرعة الاتصالات: حيث أنها تساعد في إمكانية إجراء الدردشة في الوقت الفعلي بسهل التواصل مع العملاء

$$
\text { وخصوصًا في وجود المشكلات. }
$$

(Advertising) الإعلان

1. الإعلان المستهدف Targeted Advertising: حيث يمكن استهداف العملاء من خلال معلوماتهم المتوفرة

بمنصات الثبكات الاجتماعية كـ (الا هتمامات Interests، أصحاب العمل Employers ومعايير أخرى Other

$$
\text { (criteria }
$$

2. إعادة الاستهداف Retargeting: حيث يمكن نتبع الزوّار - غير العملاء - بهدف استهدافهم كعملاء محتملين وتتوفر عدة خيارات لهذا منها أدوات بإمكانها تتبع هؤ لاء الزوار وبالتالي عرض إعلانات مباشرة لهم باستخدام

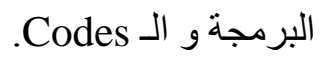

• • ترويج المحتوى (Content Promotion) 1. طريقة سهلة لتوزيع المحتوى Distribute Content: حيث تعتبر منصات الثبكات الاجتماعية من القنوات

$$
\text { الر ائعة للمساعدة في نشر المحتوى المتنوع. }
$$

2. المحتوى المقدم من المستخدمين User-Generated Content: حيث يمكن للعملاء / المستخدمين عمل

$$
\text { المر اجعات و الترويج من خلال المشاركات عبر هذه المنصات. }
$$

3. الانتثار الفيروسي للمحتوى Make Content Go Viral: حيث أن منصات الثبكات الاجتماعية هي الوقود

الذي يجعل المحتوى ينتشر بسرعة مما جعل عبارة " الانتقال الفيروسي " (Going Viral) تصف انتشار

المحتوى عبر هذه المنصات.

\section{\$ تحليات الثبكات الاجتماعية}

وضتح (Gartenstein, 2018) أن من أبرز تحديات منصات الثبكات الاجتماعية:

1- لابد أن تكون رسالة التو اصل الاجتماعي و اضحة و مركزة Focusing Your Message

2- نكريس الاهتمام الكافي Dedicating Sufficient Attention

Advertising Competition مسابقة / منافسة الاعلانات

4- خيبة أمل التو اصل الاجتماعي Social Media Disillusionment 
على الرغم من انتشار وسائل التواصل الاجتماعي، إلا أن لها جانبًا مظلمًا يحتوي على ارتباطات سلبية في أذهان العديد من

المستقيدين وخصوصًا ما يتعلق بانتهاك الخصوصية Privacy Violation.

ويذكر موقع الأعمال التابع للحكومة الأستر الية التحديات / العيوب كما يلي:

1- انخفاض / عدم تحقق الفو ائد نظرًا لعدم وجود استر اتيجية واضحة للتسويق أو للشبكات الاجتماعية.

2- إدارة الحضور عبر الإنترنت بفعالية قد بتطلب موارد إضافية.

3- الحاجة إلى المر اقبة اليومية واللحظية نظرًا لطبيعة هذه المنصات.

(Pros and cons of using social media for business, 2018).

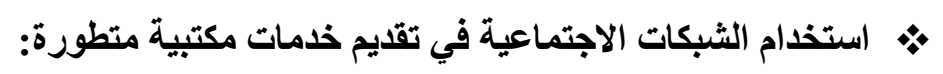

ذكر (الرندي،2017) و (مجاهد،2010) الخدمات التي تقدم من خلال هذه الثبكات كالتالي:

$$
\begin{aligned}
& \text { 1. خدمة الرد على الاستفسار ات وأسال أمين المكتبة (الخدمة المرجعية). } \\
& \text { 2. خدمة الإحاطة الجارية و إعلام المستفيد. } \\
& \text { 3. خدمة البث الانتقائي من خلال المجمو عات. } \\
& \text { 4. خدمات نشر الأحداث المهمة. }
\end{aligned}
$$$$
\text { 5. توفير بعض الروابط للكتب الإلكترونية أو المقالات المتاحة على الإنترنت. }
$$

6. توفير حلقات نقاش وتحاور بين المجمو عات حيث يتم مشاركة موضو ع معين ويسنطيع جميع الأعضاء المشاركة

$$
\text { في إبداء الر أي فيه وخدمة عمل مجمو عات اهتمام. }
$$

7. خدمات الدورات التدريبية للمستفبدين عن طريق موقع الثبكة.

\section{• أهم وأشهر وسائل التواصل الاجتماعي}

لقد تعددت تطبيقات وأنشكال وسائل التواصل الاجتماعي التي تطبق مفهوم التسويق الفيروسي من خلالها، مثل: لينكد إن

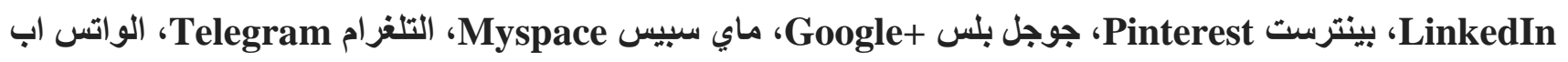

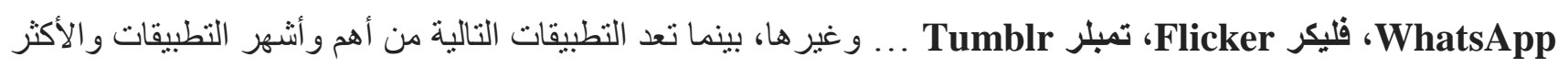
استخداما في العالم أجمع، وهي:

1. تويتر Twitter: تقوم فكرة تويتر على تقديم خدمة (التدوينات المصغّرة)، بشكل يسمح لمستخدميه بإرسال تحديثات أو ما يسمى TWEETS أو التغريدات عن حالتهم أو آرائهم أو الأنشطة التي يمارسونها في هذه اللحظة بحد أقصى 280

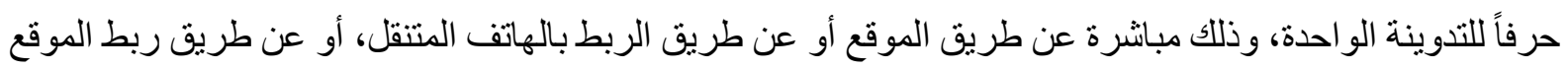
بمو اقع اجتماعية أخرى مثل الفيسبوك و غير ها، وقد جرى تفعيل اللغة العربية عام 2012 و الذي اتاح للمستخدم الاطلاع على جميع الاهتمامات التي يتابعها، عن طريق متابعته FOLLOW للصفحات التي يهتم بها، حيث يمكنه متابعة جميع التحديثات في المو اقع التي يفضلها، و التعليق عليها ومشاركتها مع أصدقائه باللغة العربية.(اللويمي، 2015). 
يتميّز الموقع بخدمة أو خاصية (الهاشتاغ Hashtag)، و هي أي كلمة تأتي بعد علامة (\#) في تويتر ، وهذه الخاصية تعمل على حصر جميع التغريدات، التي تتكلم عن موضوع معين، فبمجرد الضغط على الكلمة المر افقة لعلامة (\#)، سيظهر تويتر كل التغريدات التي تحتوي على هذا (الهاشتاغ)، وقد أعلن موقع الفيسبوك أخيراً نيته تفعيل هذه الخاصية من خدماته. (الزمل، 2014)

2. الانستغرام Instagram: هو برنامج يمكن أن تضع به صور وفيديو و التعليق عليهم وتشارك مع أشخاص من كافة

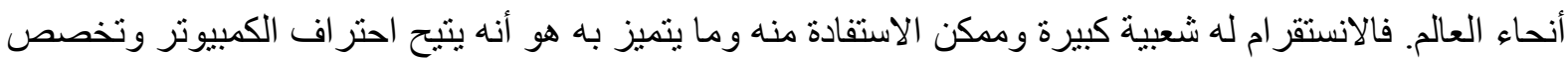
لكل مناسبة البوم لنتشر فيه الصور وير اها جميع الأحباب أو المرتمين في نفس التخصص بالإضافة إلى إمكانية التعديل على الصور و إضافة تأثيرات عليها عن طريق أدوات مختلفة لمعالجة الصور، الفلاتر المخصصة للمبتدئين، و الخبر اء

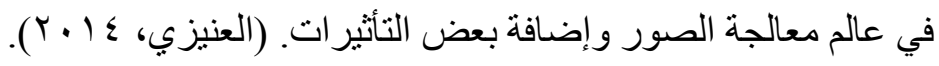

3. فيس بوك Facebook: هو موقع اجتماعي أطلق في عام 2004، يسمح هذا الموقع للمستخدمين بالانضمام إلى عدة شبكات فرعية من نفس الموقع، تصب في فئة معينة مثل منطقة جغر افية معينة، و التي تساعد على اكتشاف المزيد من الأشخاص الذين يتو اجدون في نفس فئة الثبكة، نم تأسيسها من قبل مارك زوكربرج طالب من هارفرد بالاشتر الك مع داستين موسكوفيتز وكريس هيوز ، وقد كانت عضوية الموقع بدايةً مقتصرة على طلبة جامعة هارفرد حتى امتدت إلى بلى

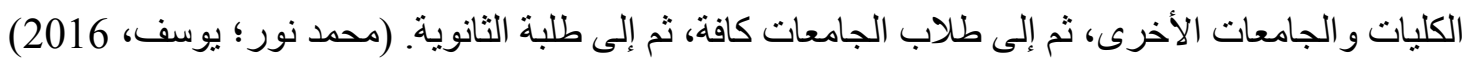
4. يوتيوب YouTube: هو موقع لعرض مقاطع الفيديو هات عبر الإنترنت تم ابتكار هـ عام 2005، فهو أكبر موقع لعرض الفيديو هات عبر الانترنت، تسمح هذه الثبكة الاجتماعية الإلكترونية للمستخدمين بتحميل ومشاركة وعرض مجموعة كبيرة ومتتوعة من مقاطع الفيديو الأصلية عبر الانترنت، ويستطيع الأفراد الوصول إلى الفيديوهات عبر المدونات

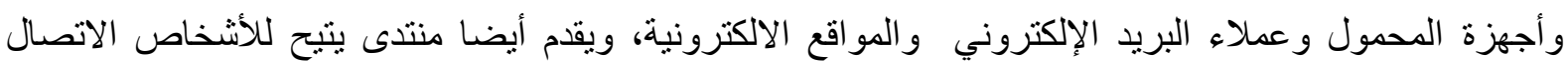
بالآخرين، و إنشاء القنو ات و الاشتر اك بها، و المحادثات الخاصة، وخاصية البحث عن مقاطع الفيديو بالكلمات المفتاحبة.

$$
\text { (عبد الهادي، 2017) }
$$

\section{• الاستفادة من قتوات التواصل الاجتماعي:}

ذكرت (Habiba \& Islam, 2015) و (عليان،2010) أن من الاتجاهات الحديثة التي اتبعتها مؤسسات المعلومات المختلفة في تقديم خدمات المعلومات هي استغلال قنوات التو اصل الاجتماعي في التو اصل مع المستفيدين و التسويق لخدماتهاوتطوير المكتبات ومر اكز المعلومات .

\section{مثال 1: فتح صفحة أو قناة خاصة على أي من تطبيقات الثبكة الاجتماعية} وذلك بهدف عرض الأنشطة التسويقية لخدمات المكتبات، والتي تتميز بما يلي: •إكانبة الوصول المباثر إلى المعلومات فضلا عن سرعة ظهور محتوى التطبيق على محركات البحث. • تجميع المنشور ات المتشابهة بالموضوع، وبالتالي يمكن التعرف على خدمات و أنشطة ممانلة لمكتبات عربية و عالمية يمكن أن تفيد المكتبات و المستفيدين على حد سو اء في التو اصل الفعال مع تلك الخدمات. 
الهجلة الدولية لنشر البحوث والدراسات

International Journal of Research and Studies Publishing
المجلد الثالث - الإصدار الثامن والعشرون تأريخ الإصدار: 20 فبراير 2022 م

ISSN: 2709-7064

$$
\begin{aligned}
& \text { •موقع مجاني ولا يحمل المكتبات أي أعباء مادية. } \\
& \text { • • }
\end{aligned}
$$

• يتيح للمستفيدين إمكانيه التفاعل مع المحتوى و إبداء الآر اء بالتعليق، فضلا عن توفير خاصية العداد التي تعرف المكتبات

$$
\text { بعدد متصفحي المحتوى. (عليان،2010) }
$$

و أوردت ( EBSCO information services, 2018 ) عددًا من النماذج لهذا الاتجاه كما يلي:

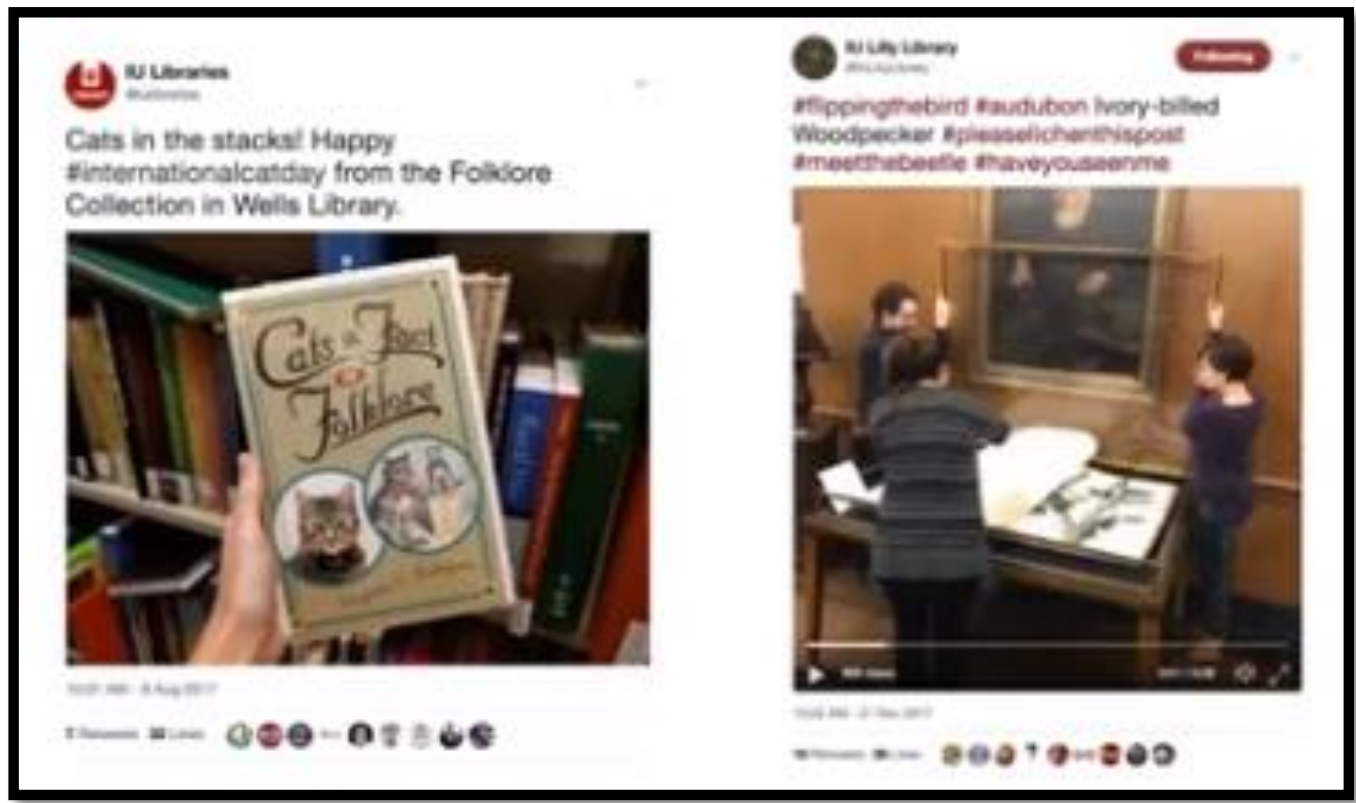

صورة (2): عرض مجمو عات المكتبة عبر تطبيق التويتر

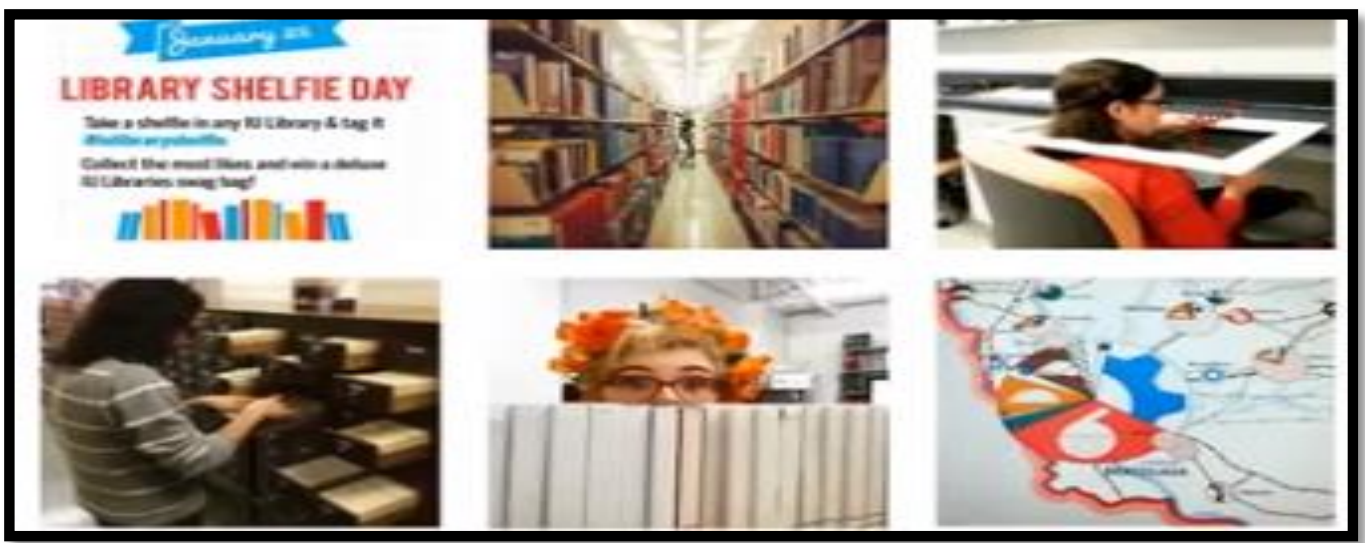

صورة (3): إقامة الحملات عبر تطبيق الانستقرام 


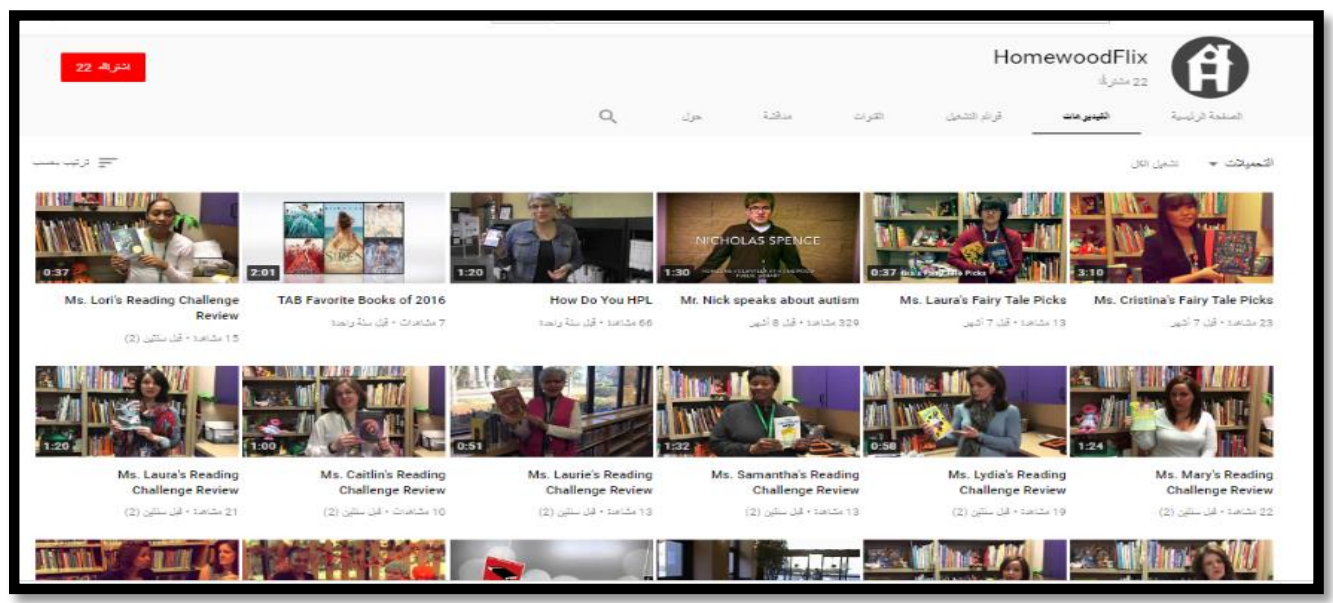

صورة (4): إنشاء مر اكز المعلومات قناة على اليوتيوب للتسويق من خلالها

مكتبة الملك فهذ الوطنية: حيث اتجهت مكتبة الملك فهر الوطنية لإنشاء صفحة خاصة بها على الثبكة الاجتماعية و إتاحة جميع الرو ابط لصفحاتها من خلال موقعها الإلكثروني الرسمي كما هو موضح أدناه:

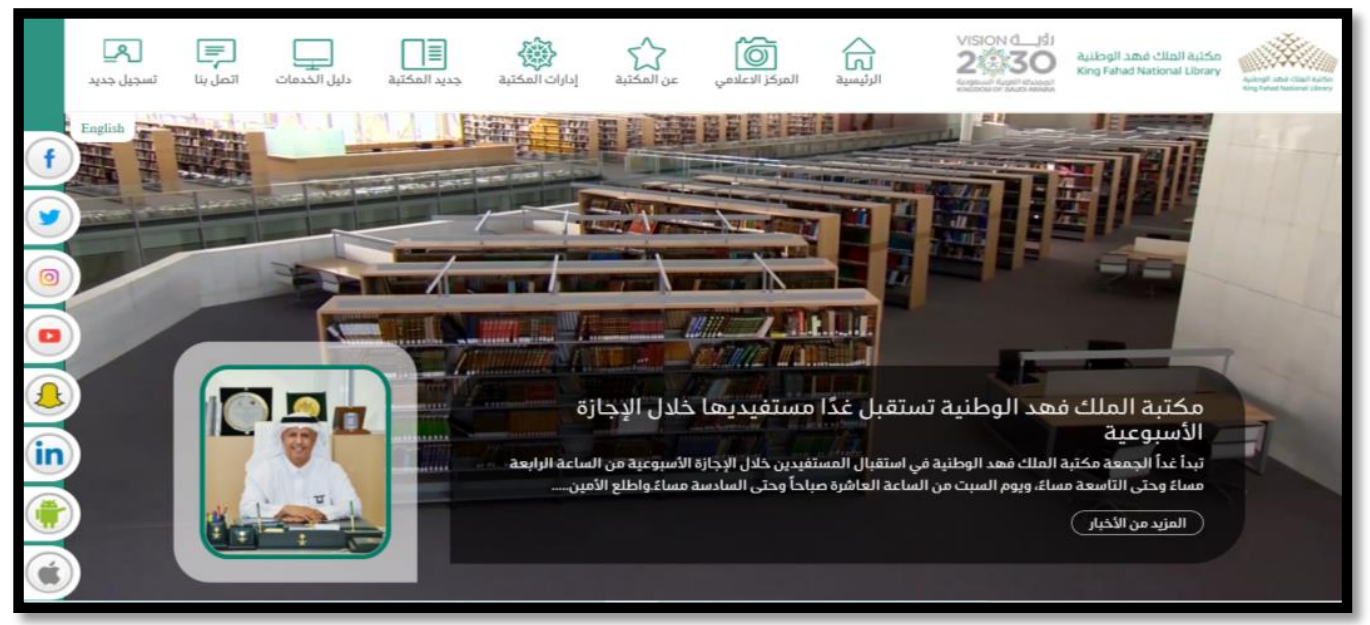

صورة (5): صفحة موقع مكتبة الملك فهد الوطنية 


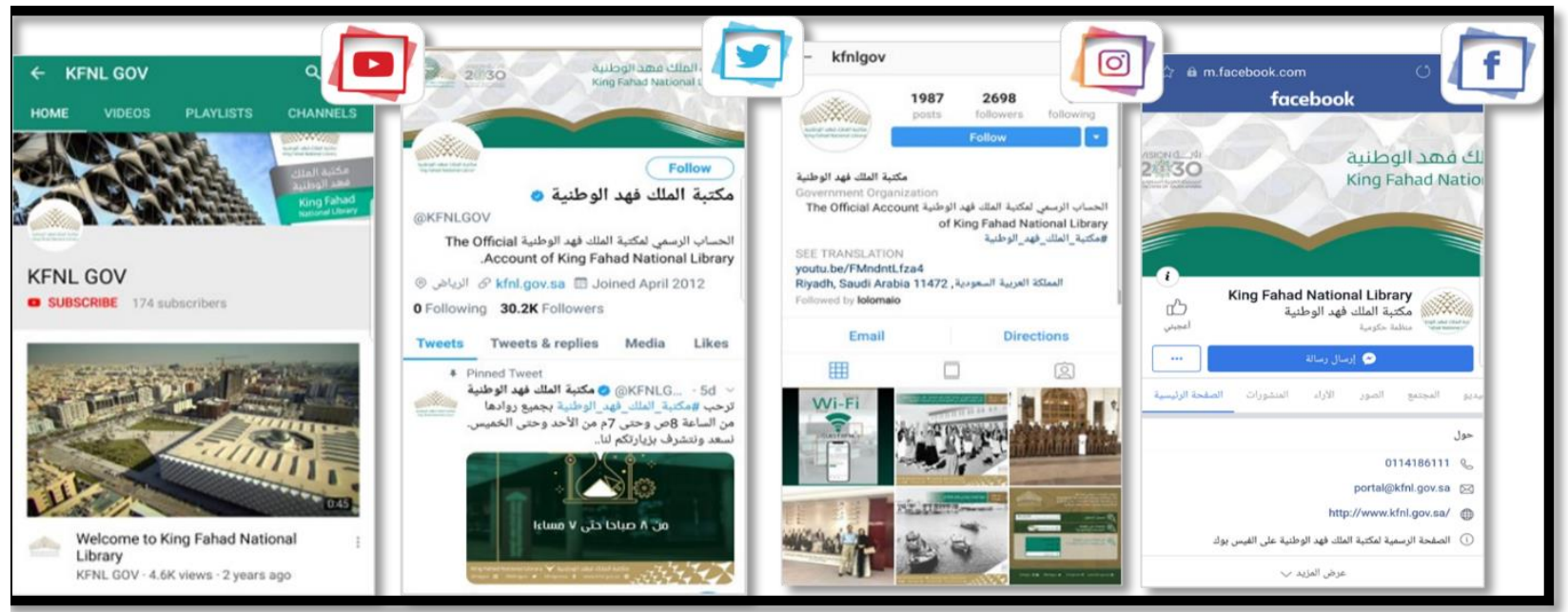

صورة (6): صفحات مكتبة الملك فهد الوطنية على وسائل التو اصل المختلفة

وجدير بالذكر أن مكتبة الملك فهر الوطنية أنشأت نطبيقًا للأجزةة الذكية وأتاحته مجانًا على متاجر التطبيقات: App Store .Play Google,

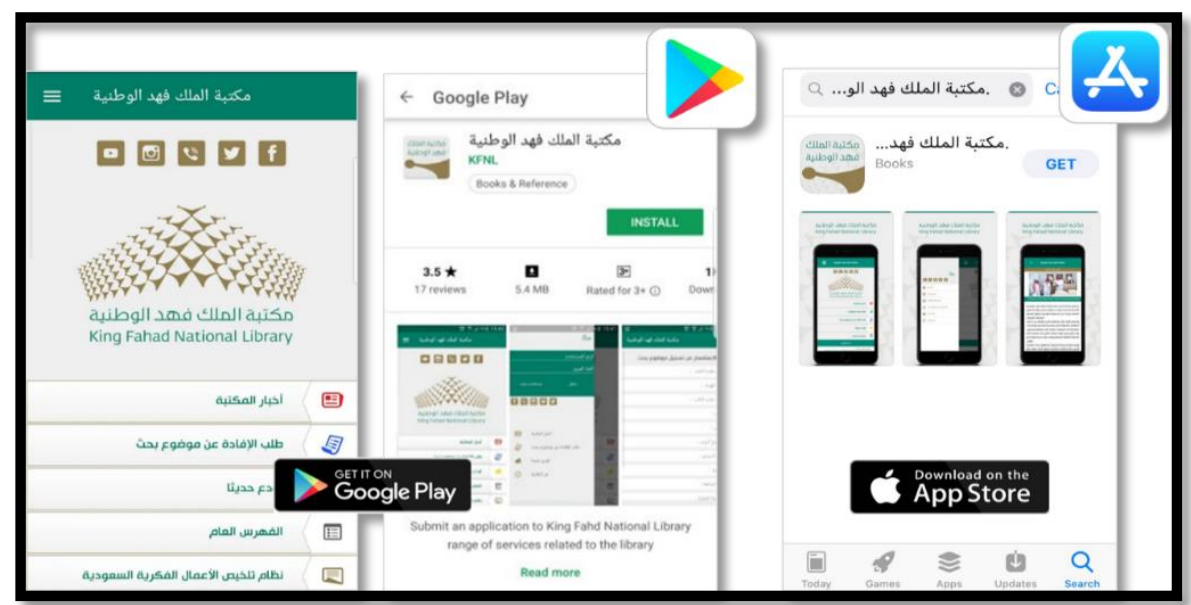

صورة (7): تطبيق مكتبة الملك فهد الوطنية على App Store و Google Play

رابعًا: الاتجاهات الحديثة التي تستخلم في تسويق خدمات المعلومات

\section{• الواقع الافتراضي (Virtual Reality)}

يعد العالم الافتر اضي من أحدث تطبيقات الويب 3.0، وهو عبارة عن تجربة بشرية طو اعية متعددة الأبعاد، تعتمد كليا أو جزئيا على الكمبيوتر، وبناء على ذلل؛؛ أطلق عليه البعض بمصطلح الانغماس البشري في البيئة الاصطناعية.

(Chatelier;Seidel,2013) 
يمكّن هذا الو اقع الافتر اضي من التسويق لمر اكز ومؤسسات المعلومات بشكل عام، أو لخداتها ومنتجاتها، وذلك لتحقيق أهداف ورؤية هذه المر اكز باختلافها، مثل زيادة عدد المستفيدين، نشر وبيع إصدار اتها، تمويلها، إقامة المؤتمرات والندوات، تقديم الدور ات والمعارض... إلخ، سو اء كان لها وجودا في العالم الحقيقي (مر اكز ومؤسسات معلومات تقليدية) أو لا (رقمية فقط). يتم التسويق عبر هذه التقنية بمختلف الأشكال، مثل: 1. إقامة الجو لات الافتر اضية التي تعرف بالمكتبة والتي يمكن مشاهدتها عبر الهو اتف الذكية. 2. تسويق أخصائي المعلومات الافتر اضي المنتسب إلى المؤسسة للخدمات التي تقدمها ومواردها المتاحة. 3. التسويق بالتعاون مع الأفتار Avatar (الثخصيات الافتر اضية) للمؤلفين و الثخصيات المهمة. 4. التسويق عبر إقامة الندوات و المؤتمرات الافتر اضية. 5. التسويق عبر إقامة معارض الكتب الافتر اضية والنشاطات و إقامة المسرحيات، و المعارض الفنية الافتر اضية. وفيما يلي بعض من الفوائد التي تلقي بظلالها على التسويق من خلال الو اقع الافتر اضي كما ذكرتها (Milićević, 2017): 1. خلق تجربة غنية Rich و غامرة Immersive وتفاعلية Interactive للمستفيد. 2. تصميم محتوى نم تخصيصه وفق احتياجات المستفيد بالضبط ويتميز بقدرنه السريعة على التكيف. 3. السماح للقر اء بالاتصال الحقيقي بالمحتوى المنشور.

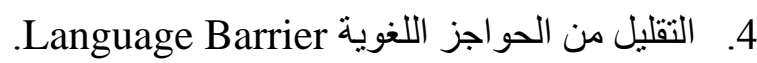
5. المساعدة في قرارات الثر اء Buying Decisions للعملاء. 6. إنشاء تحليلات مفصّلة لفهم سلوك المستخدم User Behavior. نموذج تطبيقي للواقع الافتراضي: لعبة Second Life، وهي لعبة في العالم الافتر اضي، تم إطلاقها عام 2003 من قبل شركة Linden Lab

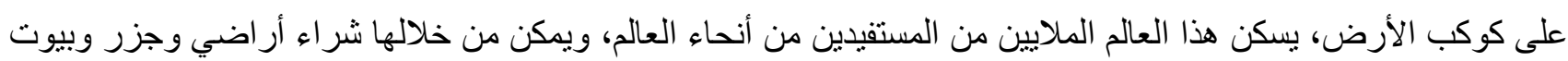
وجامعات ومر اكز معلومات افتر اضية بعض منها مرتبط لنسخة فعلية لها على أرض الو اقع.

العديد من الثركات العالمية الكبرى قامت بفتح فروع لها هنالك مثل Toyota، فضلا عن دولة السويد التي قامت بافتتاح سفارتها فيها، وتعتبر جامعة الملك سعود أول جامعة عربية و إسلامية لها نسخة في العالم الافتراضي.

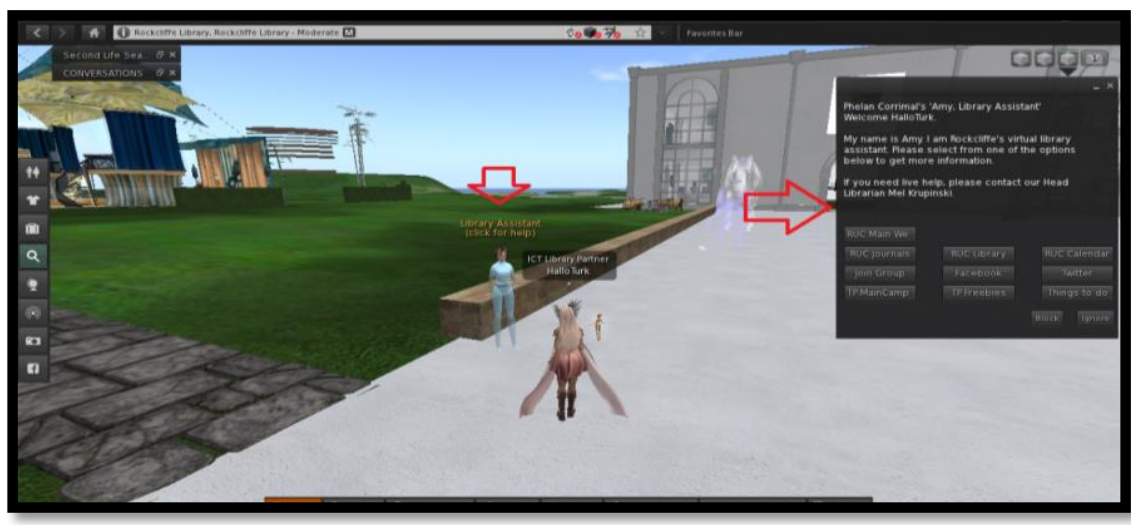

صورة (8): تسويق أخصائي المعلومات لخدمات مكتبة Rockcliff الافتر اضية 


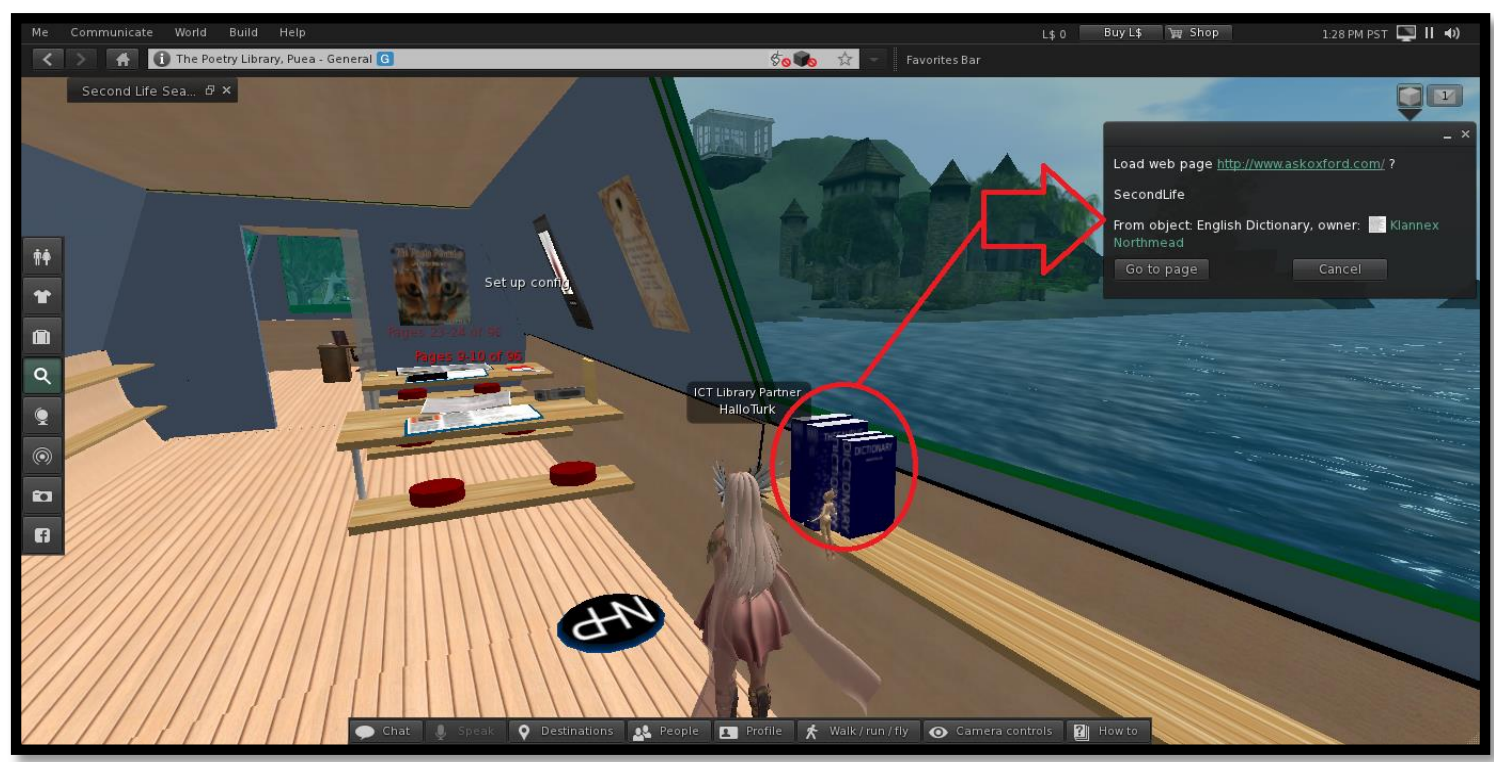

صورة (9): التسويق عبر ربط المصدر الافتر اضي بالموقع الرسمي الناشر له بمكتبة The poetry Library

\section{(Augmented Reality) الواقع المعزز)}

يمكن وصف الو اقع المعزز بأنه يجمع بين عالم حقيقي و افتر اضي، فهو يجلب سياق العالم المادي الحقيقي مع طبقة متداخلة من المعلومات الافتر اضية المعززة.

يسمح الو اقع المعزز لمستخدميه بالارتباط تماما بالبيئة الحقيقية بينما في الوقت ذاته مرتبط بعناصر افتر اضية معززة مثل الناس، الصور ، الفيديو، المو اقع، الأفاتار Avatar و العناصر ثلاثية الأبعاد. (Fecich,2014) يعتبر استخدام تقنية الواقع المعزز بحد ذاته تسويقًا نظرا لأثره الكبير في جذب المستفيدين والترويج عن مؤسسات ومر اكز

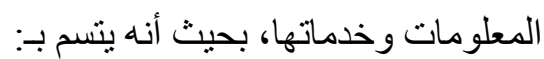

1. الخصوصية: يتيح الواقع المعزز لمؤسسات ومر اكز المعلومات توجيه الإعلانات بشكل مخصص لكل عميل على

$$
\text { حده و إضافة ميزة التجربة بشكل خاص. }
$$

2. الابتكار: الو اقع المعزز هو أحدث الأدوات التكنولوجية، ويعد من أهم الأدوات التي تتيح فرص و اسعة من الابتكار

$$
\text { فى شكل ومضمون المحتوى المقدم للجمهور. }
$$

3. المشاركة الاجتماعية: يتيح الواقع المعزز مشاركة المحتوى على وسائل التو اصل الاجتماعي ومشاركة التجارب

$$
\text { بشكل تفاعلي. }
$$

4. إمكانية التنفيذ: تتيح هذه التقنية للمستفيدين الذين لبس لديهم المهارة التقنية من إمكانية تنفيذ وخلق منتجات خاصة 
بحيث يتيح الو اقع المعزز تجارب تتمتع بالتفاعل والجذب و عناصر المرح و المتعة. و هذه العو امل ستجعل من هذه التقنية أمر ا منتشر ا فى الايام القادمة والتى سيكون لها الاثر الكبير فى إنتاج الثركات وزيادة أعداد المستفيدين.

$$
\text { (المصري، 2017) }
$$

\section{نموذج تطبيقي للواقع المعزز:}

Microsoft Hololens وهي منصة حوسبية للو اقع المعزز على شكل نظار ات ذكية تلبس بالر أس من نطوير و إنتاج شركة ميكروسوفت Microsoft تُمكّن التطبيقات من دمج و مزج العناصر و الأجسام المادية الملموسة في العالم الحقيقي مع العناصر

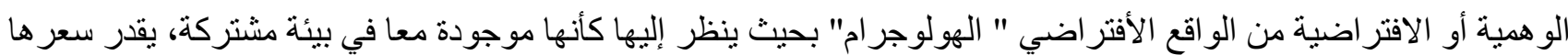

$$
\text { بـ3000 دو لار أمريكي. }
$$

وتمكن هذه التقنية أيضا من بناء البو ابات الافتر اضية حتى تتمكن الثخصيات الأخرى حين تنقلها عبر البوابات بالمرور إلى هذه المر اكز وتفقدها، وبالتالي يمكن لمؤسسات ومر اكز المعلومات التسويق و الترويج عن نفسهاو وعن مواردها وخدماتها التي تقدمها من خلالها. (Matrix inception, 2017)

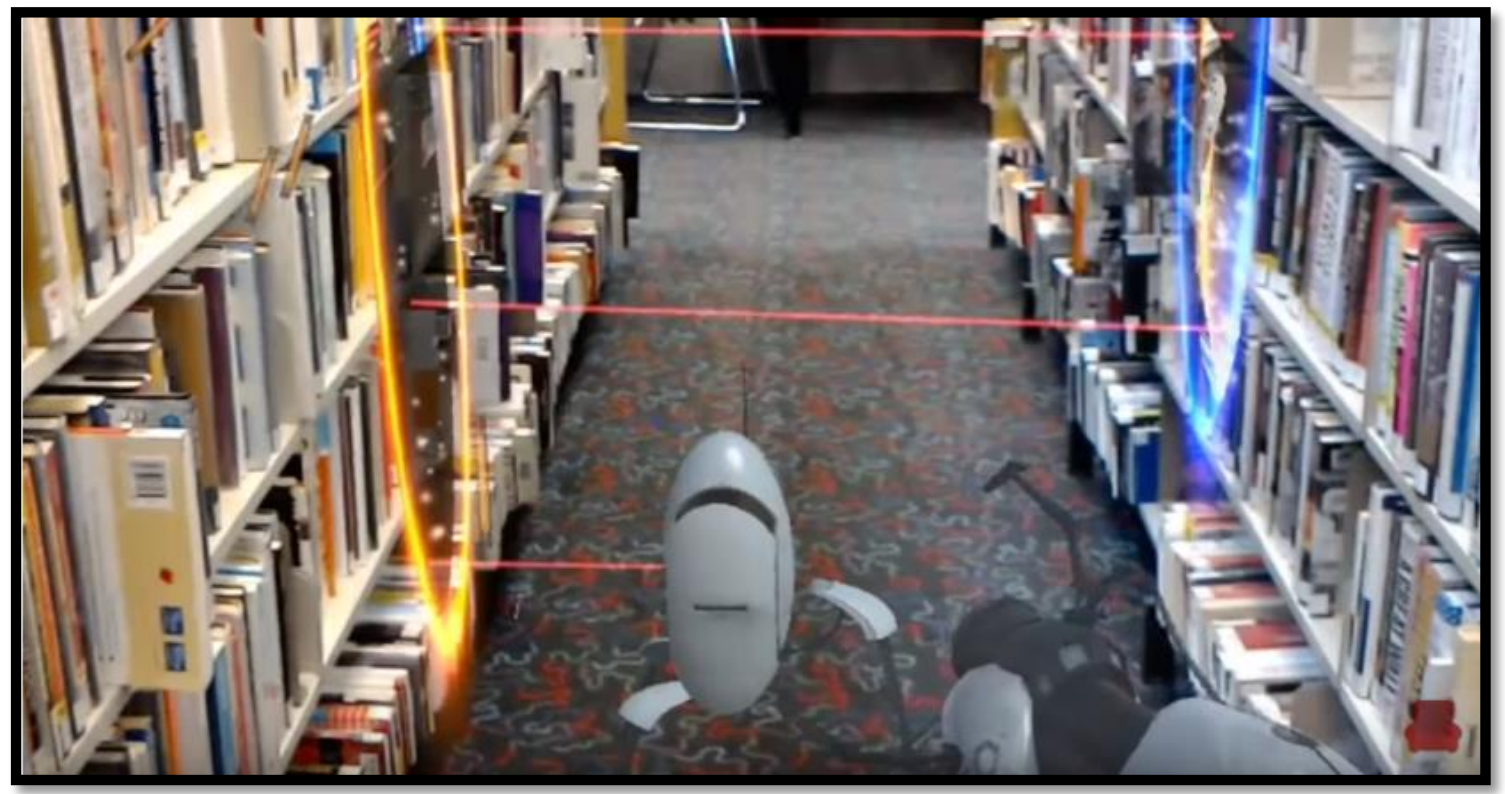

صورة (10): بناء البوابات الاففراضية عبر الو اقع المعزز من خلال Microsoft Hololens

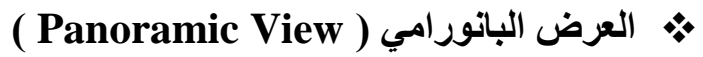

و هو عرض متتابع ومتصل - قد يتخلله شرح - يتكون من سلسلة من الصور أو لقطات من صور الفيديو يتيح للمستفيد زيارة المكتبة و التعرف على قاعاتها ومو اقع الخدمة فيها، و لا يتم التحكم فيه أو توجيهه بو اسطة المستفيد وهو يستخدم من قبل المكتبات عوضاً عن الزيار ات التعريفية التقليدية التي يقودها أخصاؤو ا معلوماتها في حضور المستفيدين من مستخدمي المكتبة. 
يركز هذا النوع من العرض في حقيقة الأمر على المباني وطرق الوصول إليها من خلال مجموعة من الصور يتم الربط بينها عن طريق وصلات، تمكن الزائر من التجول يمنة ويسرة داخل كل صورة ومن ثم الانتقال للصورة الأخرى عبر النقر على وصلة أخرى و هكذا ... بدأ استخدام هذه التقنية في بادئ الأمر في المتاحف و المطار ات ومر اكز التسوق ثم تبنتها المكتبات ومر اكز المعلومات، بداً بأمريكا وأوروبا، ثم شرعت بعض دول آسيا في استخدامها. قلما تجد في الوقت الحاضر بين مكتبات الجامعات الأمريكية أو الأوروبية على وجه التحديد من لا تسوق من خلال مو اقعها على شبكة الانترنت (الحسيني؛ عبد الرحمن، 2013)

\section{نموذج تطبيقي للعرض البانورامي:}

Culturama لتخلق شاشّة تمثّل بانور اما التاريخ، وبفضل تفاعل الثاشات معًا، يمكن الاستكثاف من خلال هذا العرض التراث المصري منذ 5000 عام وحتى يومنا هذا، كما يلقي الضوء على التراث المصري القديم والتراث القبطي والتراث الإسلامي ويعرض نماذج

هذا بالإضافة إلى إلقاء الضوء على أهم المزارات السياحية بالإسكندرية، من خلال خريطة تفاعلية توضح تراث المدينة العظيم، ويقدم هذا العرض مجاناً لمدة 15-20 دقيقة جميع ايام الاسبوع ما عدا أيام الجمعة والسبت و العطلات الرسمية (بانور اما حضارية

مصرية باتساع العالم، 2015)، (Culturama)

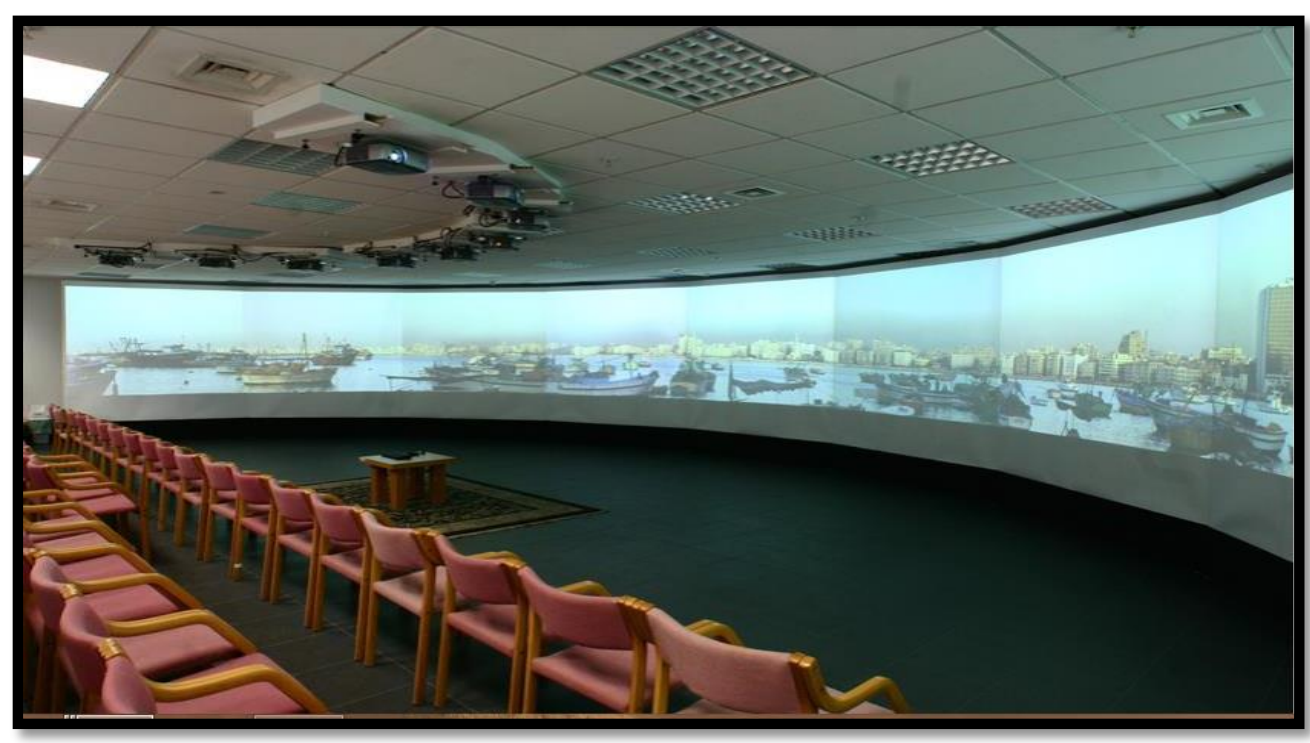

صورة (11): عرض Culturama البانور امي

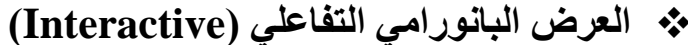

الذي يتكون من عرض بانور امي بالإضافة إلى تقنية الو اقع الافتر اضي التي تمكن المستفيد من التحكم فيه والتحرك بداخلها وهو عرض تم تطويره بدمج بانور اما الوصف إلى جولة تستخدم الو اقع الافتر اضي يتم من خلال استخدام أنواع من التصوير الإعلامي باستخدام كامير ات بموجب برنامج ثلاثي الأبعاد يقوم المستفيد بنوجيهه و التحكم فيه بنفسه باستخدام جهاز الحاسوب لمبرد 
و التنقل في كل جو انب المكتبة بصورة تفاعلية كاملة يتعرف من خلالها على مبنى المكتبة ومجمو عاتها من المصادر و الخدمات

$$
\text { نموذج تطبيقي للعرض البانورامي التفاعلي: }
$$

تجربة مكتبات الجامعة الوطنية السنغافورية حيث استخدم فيها البرنامج ثلاثي الأبعاد بصورة تفاعلية كاملة للمكتبات الخمس

$$
\text { التي تتبع للجامعة الوطنية لسنغافورة.و تتيح هذه التجربة للز ائر لموقعها: }
$$$$
\text { - - التجو ال الثخصي بين كل مر افق المكتبات. }
$$

ـ ـ ـ البحث باستخدام دليل لكل المو اقع داخل المكتبات.

$$
\text { - - البحث عن موضع أو موقع بعينه داخل المكتبات. }
$$

- القيام بجولة تعريفية يحدد مسار ها الز ائر بنفسه داخل المكتبات.

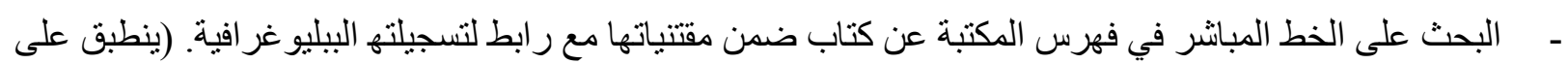

$$
\text { المكتبة المركزية فقط ) }
$$

- - لقد تم بناء مشروع المكتبة الوطنية على محرك بحث Google Earth الذي يتيح استخدام أدوات تمكن من التحرك

$$
\text { يمنة ويسرة وأسفل و أعلى إلى جانب تكبير الصور وتصغير ها مع اضافة الوصلات الثارحة ووصلات الصور }
$$

و الأفلام. و هذا يتطلب تحميل برنامج ذو سعة كبيرة (35 Bite/Mega) لتشغيل الملفات. (الحسيني؛ عبد الرحمن،

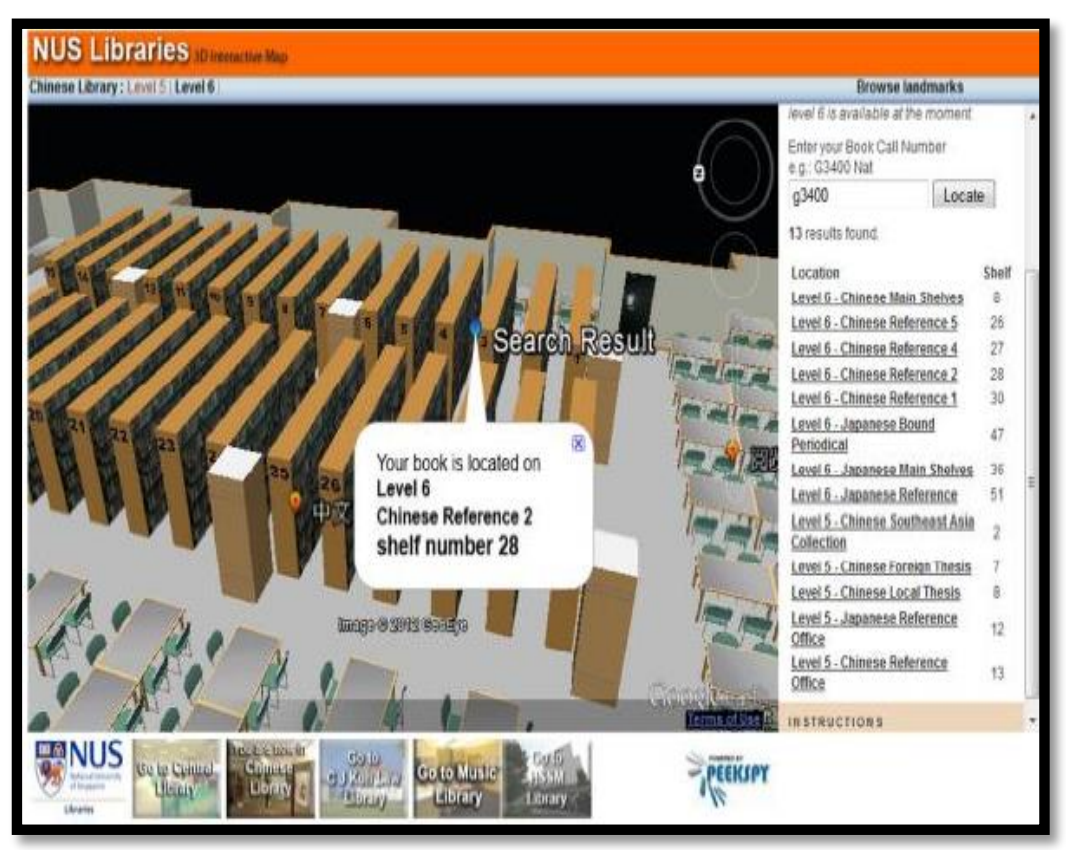

صورة (12): نموذج من صفحة احدى مكتبات الجامعة الوطنية السنغافورية ويتضح استخدام محرك Google Earth في

$$
\text { التحكم بالزيارة }
$$




\section{) الهولوجرام ( Hologram )}

تتألف الكلمة اليونانية hologram من المقطعين holos بمعنى "التصوير الثشامل" وgram بمعنى "المكتوب". و الهولوجرام تسجيل ثلاثي الأبعاد لتداخلات بين موجات ضوء الليزر. (القحطاني؛المعيذر،2016)

عبارة عن صورة ثلاثية الابعاد التي يتم تشكيلها من خلال تدخل أنشعة ضوئية من الليزر أو أي مصدر منماسك للضو ء(الز هيري،2014).

مجالات الإفادة من تقية الهولوجرام: نتطرق أولَا لاستخدام تقتية الهولجرام بشكل عام في عدة مجالات كما ذكرها (الز هيري،2014) :

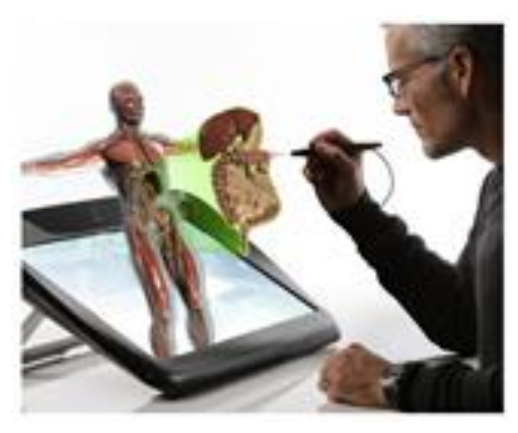

من خلال اعادة تمثيل اعضاء الجسم البشري بصيغة ثناثية الابعاد وبالاعتماد على تكنولوجيا من اجل الافادة منها في مجال تنفيذ العمليات الجر احية و التشريح في

$$
\text { مر احل التدريب و الاختبار. }
$$

اذ اصبح بإمكان الطبيب اجر اء العملية الجر احية في مرحلة تجرييية قبل تتفيذها فعلياً وبصورة افتر اضية تحاكي الو اقع تماماً.

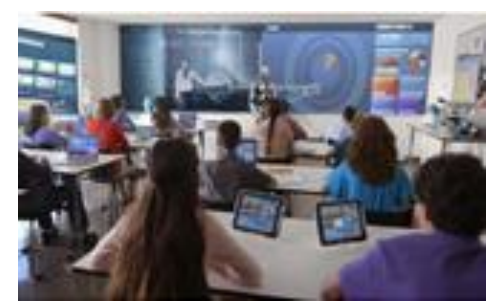

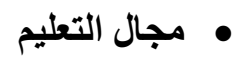

إذ اصبح بالإمكان ان يكون الأستاذ حاضر بصفته الهولوجر امية في أي فصل

$$
\text { در اسي بغض النظر عن المكان و الزمان. }
$$

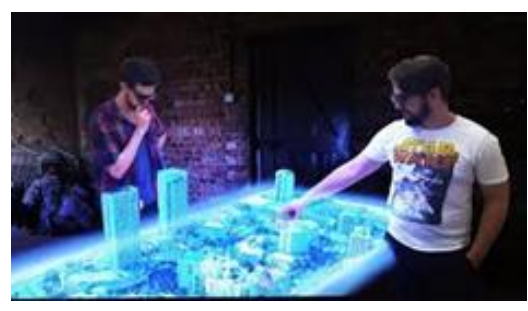

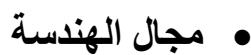

اصبح بالإمكان تحويل الرسو و المخططات الهندسية للمباني إلى مجسمات ثلاثية الابعاد يمكن مشاهدتها و التعديل عليها مباثرة من خلال تطبيقات حاسوبية وهي بديل عملي للنماذج الهندسية التي كانت شائعة وهذا الحال ينطبق على تصميم السيار ات و الطيار ات و التصاميم الهندسية الاخرى. لونيل

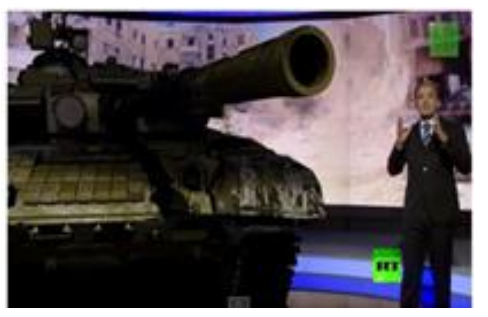

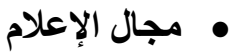

حيث يتم بث الاخبار و البر امج عبر الدمج بين الصورة الو اقعية والصورة المجسمة و أصبحت فنوات التلفاز تنافس بعضها في استخدام تقنية الهولوجر ام. 

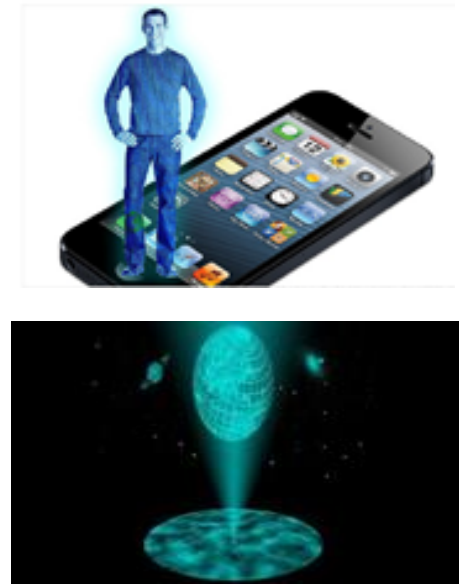

صورة ( 1 ) ): استخدام تقنية

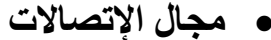

اذ يتوقع ان تدعم الهو اتف الذكية الجديدة تقنية الاتصال الهولوجر امي الذي

يمكن المتصلين من مشاهدة البعض بصورة ثلاثية الأبعاد.

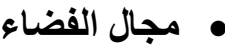

اذا لم لم يعد السفر بين المجر ات او محاكات بيئة المريخ جزء من الخيال العلمي بل اصبح اقرب إلى الحقيقة.

\section{ويوضح النموذج التطبيقي التالي استخدام تقتية الهولوجرام في التسويق:}

هناك تطبيقات حقيقية في مجال الكتب بصيغة الصورة الضوئية المجسمة في عام 2011 قدمت شركة Mediascreen منظومة متكاملة لعرض الكتب الرقمية في صيغة الكتب الضوئية المجسمة مع قابلية التصفح و أطلقت عليها اسم monkey book وبدأ الاستخدام التجريبي لها في الاسو اق و المطار ات والمتاحف وبحدود ضيقة في بعض المكتبات لعرض الكتب التر اثية. تعتمد على تقنية الهولوجر ام إذ يمكن من خلال العارضة إعادة تمثيل الكتب المخزنة رقمياً في المشغل الموجود اسفل العارضة ويتم البث الضوئي على اسطح زجاجية تفاعلية تعمل بخاصية اللمس و تكنولوجيا Retina Display تجاوز حدود المعلومة النصية والصورية التي تقدما الكتب الورقية والرقمية إلى مفهوم اشمل وهي الكتب بالوسائط المتعددة تلك الخاصية سوف تمكن الكتاب مستقبلاً من إثر اء المعلومات النصبة بالصور ومقاطع الفيديو و الصوت في وحدة موضو عية متكاملة.

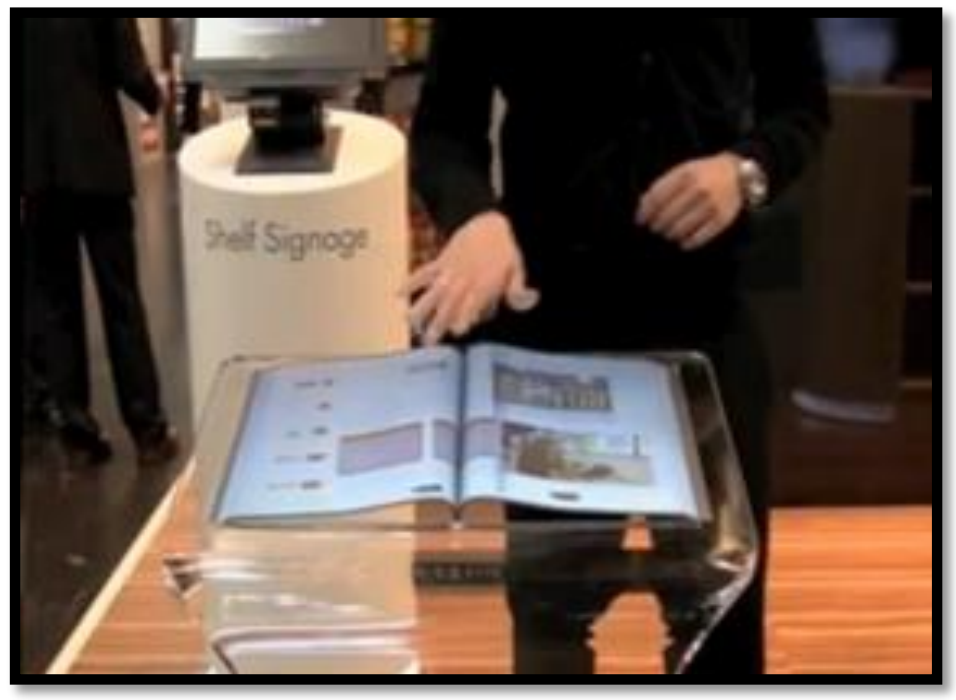

$$
\text { صورة ( } 2 \text { ): نموذج ترويجي للكتب بتقنية الهولوجرام }
$$


• تصميم وبناء موقع خاص بتسويق خدمات المعلومات بالاعتماد على نظم إدارة المحتوى

تعثبر نظم إدارة المحتوى من أنسب النظم لممارسة الأنشطة التسويقية حيث أنها نتيح للمستفيدين المشاركة والتفاعل المباثر مع الخدمات المقدمة من خلالها، فضلا عن دور ها في اثر اء المحتوى تحت رقابة المكتبة بالمعلومات القيمة التي من شانها أن تعطي المستفيد دور في اختيار المعلومات ومصادر ها. بالمقابل تعطي المكتبة فرصة للتعرف على مستفيدها ونو عية رغباتهم .. على سبيل المثال يمكن ان تستكثف المكتبة درجة اهتمام المستفيدين بخدمة او معلومة معينة من خلال عدد القر اء للمحتوى الخاص بها.

مثال:تقدم شركة Bowker المزودة الر ائدة في تقديم البيانات الببليوجر افية في العالم بعض الخدمات الر ائعة التي تربط الناثرين، المؤلفين، و بائعي الكتب بالمستفيدين القراء، بحيث أنهاوفرت أدوات تساعد المؤلفين على ترويج و بيع كتبهم، منل:

\section{https://www.book2look.com/book/XvuRnf1GTP: Book2Look خدمة}

تتيح هذه الخدمة إمكانية مشاركة المر اجعات، مقاطع الفيديو، الصوتيات، روابط التسوق والمزيد، فهو يضع المسؤولية على المؤلف أو من بيده عملية التسويق للكتب بإدارة جميع الأنشطة الترويجية عبر الانترنت وتعديلها وتقييمها من منصة و احدة و على مدار 24/ 7. فهي أداة تسويقية تمنح التحكم الكامل في البيانات الببليوجر افية والمو اد الترويجية الخاصة بكل كتاب، و عرضها في أي وقت وفي أي مكان، تباع هذه الخدمة بقيمة 200 دو لار و التي تعتبر غبر مكلفة نظر الفائدتها

$$
\text { التي ستعود لمستخدمبها. }
$$

خصائص Book2Look: Bak

1. حلا مثاليا للترويج عبر الانترنت، بحيث أنه جمع كل المو اد الترويجية على نظام واحد.

2. سهولة وسر عة إنشاء عينة من الكتاب وتكون تفاعلية وسهلة البحث من خلالها.

3. متاحة لجميع تجار التجزئة عبر الإنترنت، المدونين والمجتمع ككل.

4. يسهل على القر اء معاينة الكتاب و العثور عليه وشر اؤه.

5. يساعد على مر اقبة النشاط و التقييمات عن الكتاب. 


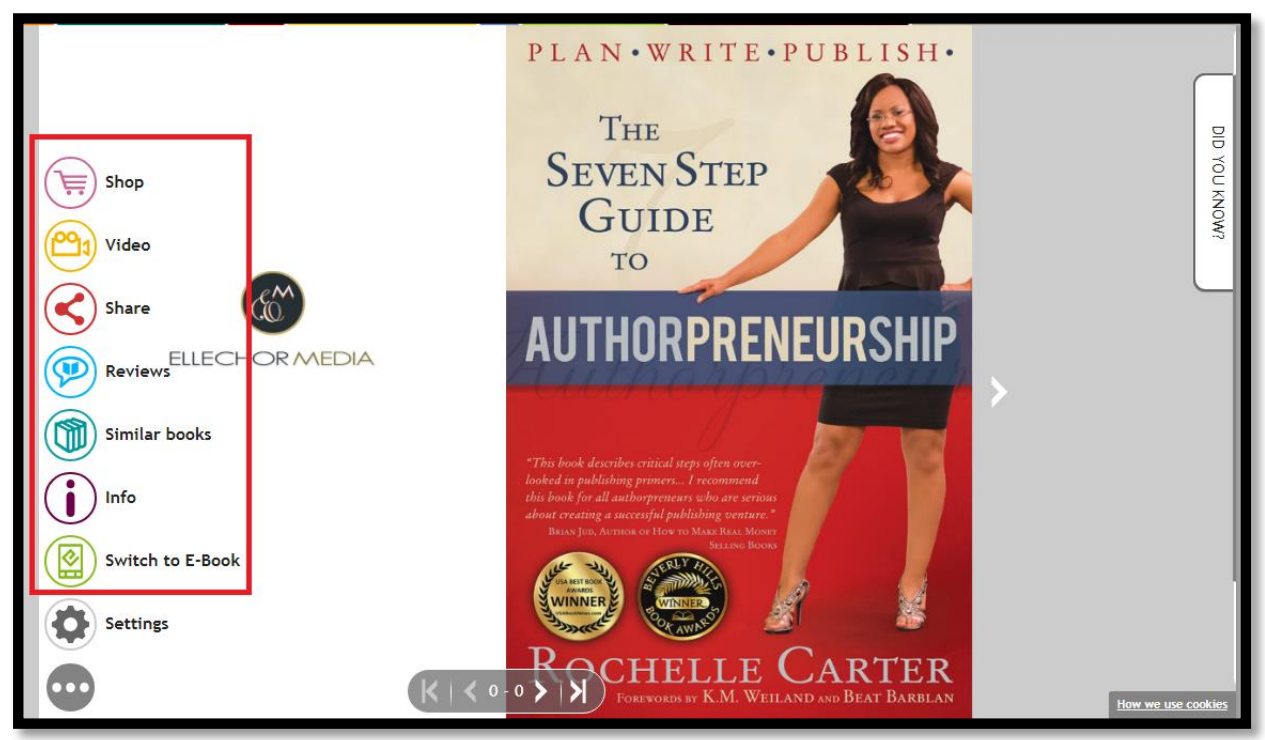

صورة (15): عينة تسويقية لكتاب ما مدعمة بخصائص تسويقية

النتائج والتوصيات:

أن الثقنيات الحديثة طريقة سريعة لنشر و الترويج لخدمات ومؤسسات المعلومات بطريقة مبتكرة وملفته وتعتبر عامل جذب للمستفيدين وطريقة حديثة لكسب العملاء و المستفيدين، حيث أن قلة من مؤسسات المعلومات أدخلت التقنيات الحديثة للترويج لخدماتها، وتعتبر نقافة التسويق لخدمات مؤسسات المعلومات تم اقتصار ها على نشر الخدمات على حسابات مواقع التواصل الاجتماعي التابعة لمؤسسات المعلومات. وتوصي الباحثات: بتكثيف الجهود لاستخدام التقنيات الحديثة في التسويق و الترويج للخدمات بإقامة الحملات وعرض الخدمات عن طريق هذه التقنيات لاستقطاب المستفيدين، و الاطلاع المستمر على التقنيات الحديثة و عمل در اسة لمدى فعاليتها، العمل على بلى تدريب العاملين و إخصائي المعلومات على التعامل مع التقنية وتبني طرق التسويق الحديثة ومعرفة أساليب التسويق وتسخيرها لترويج لخدمات مؤسسات المعلومات.

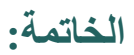

يظهر جلياً بوجود منافسة في الابتكار لتقديم خدمات المعلومات و الترويج لها في مؤسسات المعلومات حيث إن الاحتفاظ بالعملاء و الإبقاء على الزو ار و المستفيدين ليس بأمر سهل في ظل هذه المنافسة وتعددت الطرق و التقنيات الحديثة في تقديم تلك الخدمات. حيث أصبح من البديهي استخدام التقنيات الحديثة والثبكات الاجتماعية في مؤسسات ومر اكز المعلومات لنؤدي مهمة التسويق ل خدماتها كما أسلفنا في بعض النماذج السابقة، حيث سيظل التسويق لخدمات المعلومات عن طريق التقنيات الحديثة من اقوى طرق التسويق و عامل جذب للمستقبدين بطرق مبهرة. 
أحمد، محمد مهدي. (2017). تقنية التسويق الفيرسى فى سوق مؤسسات المعلومات: النشأة. التطور . المستقبل .المؤتعر الثامن والعشرون للاتحاد العربي للمكتبات والمعلومات بعنوان: شبكات التواصل الاجتماعي وتأثير/تها في مؤسسات المعلومات في الوطن العربي - مصر، القاهرة: الاتحاد العربى للمكتبات و المعلومات ( اعلم )، 1 - 15. مسترجع من http://search.mandumah.com/Record/853740 احديد، سكينة مصباح. (2013). تسويق خدمات المكتبات و المعلومات ـمجلة كلية الآداب: جامعة طر ابلس ـ كلية الآداب، ع22، 150. 133

http://search.mandumah.com.sdl.idm.oclc.org/Record/994872 بامفلح، فاتن (2009) ـ خدمات المعلومات في ظل البيئة الالكترونية ـ القاهرة: الدار المصرية اللبنانية. ص 86 -103 مسترجع http://search.mandumah.com/Record/44527 من بانور اما حضارية مصرية باتساع العالم (2015). المكتبة السعودية الرقمية. تاريخ الاطلاع: 17-10-2018. ر رابط الاسترجاع: https://sdl.edu.sa/SDLPortal/ar/post.aspx?p=8341

الحسيني، محمد؛ عبد الرحمن، مهدي (2013). دور اختصاصي المعلومات في التسويق الإلكتروني لخدمات المعلومات بمكتبة حصن الثموخ. المؤتمر التاسع عشر لجمعية المكتبات المتخصصةـ فرع الخليج العربي: مستقبل المهنة: كسر الحواجز التقليدية لمهنة المكتبات و المعلومات و التحول نحو مستقبل البيئة المهنية الرقميةـ الإمارات. تاريخ الاطلاع: 17http://search.mandumah.com/Record/383835: 2018-10. رابط الاسترجاع: الحياري، إيمان (2018). مفوم تسويق المعلومات. موضوع، أكبر موقع عربي بالعالم. تاريخ الاطلاع: 17-10-2018 رابط https://bit.ly/3swYqdk

الخالدي، منصور عيدان عكرب. (2018). تسويق خدمات المعلومات في المكتبات ومراكز المعلومات: المكتبة المركزية أنموذجا .مجلة الأطروحة للعلوم الإنسانية: دار الأطروحة للنشر العلمي، س3، عالعيف 11، 147 .172 - مسترجع من

\section{http://search.mandumah.com.sdl.idm.oclc.org/Record/94334}

$$
\begin{aligned}
& \text { خبر اني، محمد علي؛ القرني، عبد الرحمن عبيد (2017). دور وسائل التواصل الاجتماعي في تسويق خدمات المعلومات في } \\
& \text { مكتبة جامعة الملك عبد العزيز. المؤتهر الثامن والعشرون للاتحاد العربي للمكتبات والمعلومات بعنوان: شبكات } \\
& \text { التواصل الاجتماعي وتأثبر/تها في مؤسسات الدعلومات في الوطن العربي ـ مصر (الصفحات 1-30). القاهرة: } \\
& \text { الاتحاد العربي للمكتبات و المعلومات (اعلم). تاريخ الاسترداد اكتوبر، 2018، من }
\end{aligned}
$$

http://search.mandumah.com/Record/853761 
الرندي، بشاير سعود. (2017). وسائل التو اصل الاجتماعي ودور ها في تسويق خدمات المعلومات في مكتبات دولة الكويت . المؤتمر الثامن و العشرون للاتحاد العربي للمكتبات والمعلومات بعنوان: شبكات التواصل الاجتماعي وتأثبر/تها في مؤسسات المعلومات في الوطن العربي ـ مصر، القاهرة: الاتحاد العربي للمكتبات و المعلومات ( اعلم )، 1 - 19. http://search.mandumah.com/Record/853821 مسترجع من:

الزمل، ناصر (2014). رقميون غيرو حياتتا: جالك دروسي مؤسس تويتر . مجلة فكر - السعودية، ع8. رابط الاسترجاع: http://search.mandumah.com/Record/517309

الزهيري، طلال ناظم. (2014). تطبيقات تكنولوجيا Hologram و أوجه استثمار اها في مجال عمل المكتبات. مجلة المكتبات والمعلومات والتوثيق في العالم العربي ـ إدارة الدعلومات والتوثيق والترجمة - جامعة الدول العربية ـ مصر، ع1 ،

$$
\text { 49 - } 36
$$

http://search.mandumah.com/Record/777863 السريحي، حسن عوّ اد (2018). مقدمة في علم الدعلومات رؤية حديثة. الرياض: الثقري. الطائي، يوسف حجيم ؛ الحكيم، ليث علي ؛ زوين، عمار عبد الأمير. (2016). إستر/تيجية التسويق الفبروسي ودورها في إدراك الزبون للقيهة. تاريخ الاسترداد اكتوبر، 2018، من مركز المنشاوي للار اسات والبحوث: http:/cutt.us/kxAlS العباس، م ع (2009) ـ تسويق خدمات المعلومات عبر الإنترنت ـ الرياض: مكتبة الملك فهد الوطنية، 2009 ـ ص 136 http://search.mandumah.com/Record/428557 مسترجع من • منترئ

عبد الهادي، سارة (2017). اتجاهات أعضاء هيئة التدريس والطلاب بالكليات العلمية في جامعة الملك عبد العزيز في العملية التعليمية YouTube نحو استخدام اليوتيوب. مجلة المركز العربي للبحوث والدراسات في علوم المكتبات

$$
\text { و المعلومات_سوريا، مج4، ع8. }
$$

العريشي، جبريل؛ الغامدي، فوزية (2015). دور مؤسسات المعلومات في عصر المعرفة لتعزيز الانتماء وتحقيق الوحدة الوطنية لاى الثباب في دول مجلس التعاون الخليجي. Annual Conference The SLA-AGC 21.

$$
\text { الاطلاع: 16-16-10 إبط الاسترجاع: }
$$

\section{http://www.qscience.com/doi/pdf/10.5339/qproc.2015.gsla.6}

عليان، ر. م (2010). خدمات المعلومات: Information services . عمان: دار صفاء. ص 527. عبد الهادي، سارة (2017). اتجاهات أعضاء هيئة التدريس و الطلاب بالكليات العلمية في جامعة الملك عبد العزيز في العملية التعليمية نحو استخدام اليوتيوب. مجلة المركز العربي للبحوث و الدراسات في علوم المكتبات والمعلومات_سوريا، 
المجلة الدولية لنشر البحوث والدراسات

International Journal of Research and Studies Publishing
المجلد الثالث - الإصدار الثامن والعشرون تأريخ الإصدار: 20 فبراير 2022 م

العنيزي، يوسف عبد المجيد. (2014). و اقع استخدام مواقع التو اصل الاجتماعي (الانستقرام والتويتير والفيس بوك) لطلبة الرياضيات والحاسوب في ضوء معايير الجودة الثاملة بكلية التربية الأساسية في دولة الكويت. الثقافة والتنمية ـ http://search.mandumah.com/Record/606302 مصر، س15، ع82، 1 - 80. مسترجع من القحطاني، أمل سفر ، و ريم عبدالله المحيذر ـ (2016).مدى و عي أعضاء هيئة التدريس بجامعة الأميرة نورة بتقنية التصوير

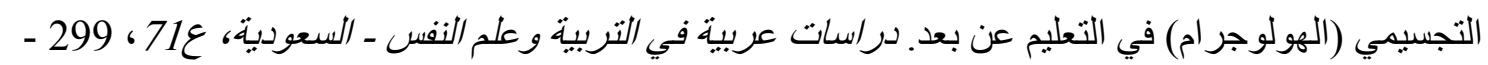

$$
\text { 333. مسترجع من }
$$

http://search.mandumah.com/Record/760849

اللويمي، أحمد محمد (2015). الجدل في تويتر: قراهة في أشكال التواصل حول القضايا الساخنة. مجلة الكلمة_لبنان، س22، $.89 \varepsilon$

مجاهد، أماني (2010) استخدام الثبكات الاجنماعية في تقديم خدمات مكتبة منطورة. در اسات المعلومات، ع8، 95- 36 مسترجع http://search.mandumah.com/Record/44527 من. الدزيج التسويقي Marketing Mix. (2009). تاريخ الاسترداد اكتوبر، 2018، من المحاسب الأول: https://www.almohasb1.com/2009/03/marketing-mix.html

$$
\text { مزيج تسويقي. (2018). تاريخ الاسترداد أكتوبر، 2018، من ويكيبديا الموسوعة الحرة: }
$$

https://ar.wikipedia.org/wiki/\%D9\%85\%D8\%B2\%D9\%8A\%D8\%AC \%D8\%AA\%D8\%

\section{B3\%D9\%88\%D9\%8A\%D9\%82\%D9\%8A}

محمد نور، مصطفى؛ يوسف، عوض الكريم (2016). شبكات التو اصل الاجتماعي: فيسبوك - تويتر - الوتساب أنموذجا.

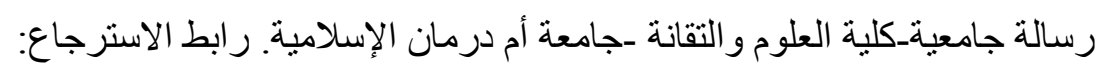

http://search.mandumah.com/Record/833017

المصري، أحمد (2017). الواقع المعزز والتسويق. موقع VR insider. Net. تاريخ الاطلاع: 15-10-2018. رابط

$$
\text { الاسترجاع: }
$$

https://www.vrinsider.net/\%D8\%A7\%D9\%84\%D9\%88\%D8\%A7\%D9\%82\%D8\%B9-

\%D8\%A7\%D9\%84\%D9\%85\%D8\%B9\%D8\%B2\%D8\%B2-

1\%D9\%88\%D8\%A7\%D9\%84\%D8\%AA\%D8\%B3\%D9\%88\%D9\%8A\%D9\%82

الهلال، محمد بن ناصر (2017). تسويق خدمات المعلومات فى المكتبات الاكاديمية فى الجامعات الحكومية السعودية عبر شبكة التو اصل الاجتماعى تويتر :Twitter دراسة تحليلية .المؤتمر الثامن و العشرون للاتحاد العربي للمكتبات و المعلومات 
بعنوان: شبكات التواصل الاجتماعي وتأثبر/تها في مؤسسات الدعلومات في الوطن العربي، 201-1القاهرة: الاتحاد http://search.mandumah.com/Record/853792 العربي للمكتبات و المعلومات ( اعلم ). تم الاسترداد من

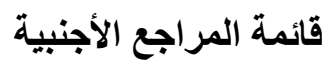

AMA (2013). Marketing. Seen in: 11-10-2018. Retrieved from: https://www.ama.org/AboutAMA/Pages/Definition-of-Marketing.aspx

Brookins, M. (2018). The Advantages of Using Social Media Marketing. Retrieved October 2018, from Chron: https://smallbusiness.chron.com/advantages-using-social-mediamarketing-18593.html

Chatelier, Paul R.; Seidel, Robert J. (2013). Virtual Reality, Training's Future?: Perspectives on Virtual Reality and Related Emerging Technologies. Defence Research Series. (6). Seen in: 11/10/2018.Retrieved from:

https://books.google.com.sa/books?id=kiPaBwAAQBAJ\&printsec=frontcover\&hl=ar\#v= onepage $\& \mathrm{q} \& \mathrm{f}=$ false

Culturama. Bibliotheca Alexandrina. seen in: 17-10-2018. Retrieved from: https://www.bibalex.org/en/project/details?documentid=295

Dukart, B. (2018, May). CoSchedule Blog. Retrieved October 2018, from 20 Important Benefits of Social Media Marketing Every Business Should Know: https://coschedule.com/blog/benefits-of-social-media-marketing-for-business/

EBSCO information services (2018). How to market your library WEBINAR. Youtube. Seen in: 17-10-2018. Retrieved from:

https://www.youtube.com/watch?v=FRCkIRlhhYo\&t=1361s

Fecich, Samantha (2014). The use of augmented reality enhanced reading books for vocabulary acquisition with student who are diagnosed with special needs. Seen n: 15-10-2018. Retrieved from: https://search.proquest.com/docview/1553782929?accountid=142908 
Gartenstein, D. (2018, June). Disadvantages of Advertising With Social Media. Retrieved October 2018, from Chron: https://smallbusiness.chron.com/disadvantages-advertising$\underline{\text { social-media-18746.html }}$

How to market Your library WEBINAR (2018). Youtube. Seen in: 17-10-2018. Retrieved from: https://www.youtube.com/watch?v=FRCkIRlhhYo\&t=1361s

Islam ‘M. M \& Habiba ‘U . (2015). Use of social media in marketing of Iibrary and information services in Bangladesh. DESIDOC Journal of Library \&Information Technology ،35 (4) Retrieved from http://search.proquest.com/docview/1721904751?accountid=142908 Jackson, D. (2017, May 02). 38 Benefits of Social Media Marketing Every Business Needs to Know. Retrieved October 2018, from Sproutsocial: https://sproutsocial.com/insights/benefits-of-social-media/

Matrix inception (2017). Portals \& Lasers in a library- Hololens. Youtube. Seen in: 15-10-2018. Retrieved from: https://www.youtube.com/watch?v=RUQULkr_ILQ

Milićević, M. (2017, November). 7 Benefits of Virtual and Augmented Reality for Your Marketing. Retrieved October 2018, from Linkedin: https://www.linkedin.com/pulse/7benefits-virtual-augmented-reality-your-marketing-milena-milićević

Pros and cons of using social media for business. (2018, July). Retrieved October 2018, from Business.gov.au: https://www.business.gov.au/marketing/social-media/pros-and-cons-of$\underline{\text { social-media }}$

Second Life (2018). Wikipedia, The free Encyclopedia. Seen in: 11-10-2018. Retrieved from: https://en.wikipedia.org/wiki/Second_Life

Weller, E. (2018). The Advantages of Social Networking Promoting a Business. Retrieved October 2018, from Chorn: https://smallbusiness.chron.com/advantages-socialnetworking-promoting-business-21990.html

Doi: $\underline{\text { doi.org/10.52133/ijrsp.v3.28.6 }}$ 